Elsevier required licence: (C) 2019. This manuscript version is made available under the CC-BY-NC-ND 4.0 license http://creativecommons.org/licenses/by-nc-nd/4.0/

The definitive publisher version is available online at https://doi.org/10.1016/j.autcon.2019.102934 


\title{
Robotic Autonomous Systems for Earthmoving in Military Applications
}

\author{
Q.P. Ha ${ }^{a^{*}}$, L. Yen ${ }^{b}$, and C. Balaguer ${ }^{c}$ \\ ${ }^{a}$ Faculty of Engineering and IT, University of Technology Sydney, NSW 2007, Australia \\ ${ }^{b}$ Land Vehicles \& Systems, Defence Science \& Technology Group, SA 5111, Australia \\ ${ }^{c}$ Robotics Lab, Universidad Carlos III de Madrid, Spain \\ E-mail: \{Quang.Ha@uts.edu.au; Leong.Yen@dst.defence.gov.au; Balaguer@ing.uc3m.es $\}$
}

\begin{abstract}
Along with increasing innovations in frontier engineering sciences, the advancement in Robotic Autonomous Systems (RAS) has brought about a new horizon in earthmoving processes for construction. In the military domain, there is also an increasing interest in utilising RAS technologies. In particular, ground-based forces are frequently called upon to conduct earthmoving tasks as part of military operations, tasks which could be partially or fully aided by the employment of RAS technologies. There have been rapid developments in military construction automation using high-mobility ground-based platforms, human-machine and machine-machine interfaces, teleoperation and control systems, data transmission systems, machine perception and manipulation capabilities, as well as advances in networked robotics and cyberphysical systems. Given these developments it is timely to undertake a comprehensive overview on the topic of interest to the research community and the authority. This paper presents an overview of the RAS development for platform-centric earthworks together with an analysis of the technical feasibility, maturity, key technical challenges, and future directions for the application of RAS technologies to earthmoving tasks of interest to the army.
\end{abstract}

Keywords

Military earthmoving; robotic autonomous systems; technology/system readiness; mode of control

\section{Introduction}

Construction tasks are employed in army operations to enhance both force and force protection. They include not only military construction tasks such as filling protective barriers, soil compaction, installing defensive walls, operating a borrow pit, dirt bunding, and excavating anti-tank ditches and infantry trenches, but also traditional civil construction tasks such as land clearance, earthmoving, resource handling, and constructing open-sealed roads and repairing routes and tracks. Due to the difficult and hazardous conditions that often prevail in military tasks, there is interest in carrying out these tasks using robotic autonomous systems (RAS), whereby autonomy is achieved partially or fully using robotic technologies. Research and development in construction processes has been active for several decades with the introduction of RAS technologies [1]. Amongst progress in engineering science, advances in RAS technologies have brought about new technical feasibility, maturity and affordability in construction automation, as well as enhanced resilience in infrastructure. Modern RAS technologies address challenges and future directions for automation in construction and its associated platforms used generally in civil engineering or recovery works in hazardous areas, e.g. from landmines, nuclear or natural disasters. For earthmoving processes, automation has been applied to such platforms as excavators, bulldozers, graders, front-wheel loaders and dump trucks. New thinking is occurring within a framework of modelling of control, 
planning and artificial intelligence with the use of sensing and information technologies [2,3] in combination with new trends in the use of RAS for construction automation [4]. To this end, a great deal of research and development has been devoted to raising the level of autonomy of the operating platforms for improving their work capacity and productivity, task efficiency as well as quality and reliability.

In army applications, RAS call upon the ability to integrate sensors, vision imaging, actuators, endeffector manipulation, computer control, human interface and platform coordination for task execution in unstructured, difficult and hazardous conditions. For ground-based tasks such as filling of protective barriers (HESCO baskets), building dirt bunding structures, as well as anti-tank ditches and trenching, a variety of heavy construction machinery such as excavators, bulldozers, wheel loaders, graders and articulated dump trucks have been customised to meet the special requirements of the military. On one hand, with the demand on combat engineering capability and more rapid rates of construction, there is an increasing requirement for the combat engineering transformation using autonomous systems. Studies in this field therefore have recently received much interest. Surveys of RAS used in military applications have been conducted [5], covering Unmanned Ground Vehicles (UGV) and air/sea-based robotic vehicles in combat and logistic operations rather than earthmoving processes. On the other hand, there has been rapid developments in human-machine and machine-machine interfaces, teleoperation and control systems, data transmission systems, perception and manipulation capabilities for high-mobility ground-based military platforms with identified technology gaps in both autonomy and human-machine interfaces in the aspects of interoperability, operator awareness, control systems and autonomy oversight [6]. To this end, recent advances in networked robotics and cyberphysical systems with enhanced capability of cooperative coordination have been promising in teaming an array of platforms and equipment for military earthmoving tasks [7]. As such, there exists a need for the authority to assess the technical feasibility, maturity, autonomy level, key technical challenges, and future directions for the application of RAS to earthmoving construction.

This paper presents an overview of the state-of-the-art of earthmoving construction automation used for army applications, proposes the mode of control for platform-centric applications of RAS in earthmoving based on the levels of technology readiness level and system readiness, and with applications in the military domain. Our main objectives are (i) to review the development of RAS technologies applied to groundbased construction platforms with reference to their technical feasibility and maturity, (ii) to analyze the level of autonomy and modes of control for the platform-centric control process in army earthmoving as well as to estimate their future direction of their application, and (iii) to particularly emphasize on the application RAS technologies to platform-based automation for selected tasks of interest in military earthworks.

The paper is organized as follows. After the introduction, Section 2 presents the taxonomy of technology maturity, the new concept for mode of control for construction platforms, and the core RAS technologies in the army construction domain. Section 3 reviews the development of these technologies along with their projections for earthmoving platforms with respect to platform-centric modes of control. By considering work capacity and task efficiency, Section 4 gives an analysis of the RAS technologies applied to earthworks tasks of interest in the military domain together with projections into future applications. Finally, a conclusion is drawn in Section 5.

\section{Technical taxonomy and core RAS technologies}

In this paper, our judgement and technical evaluation are based on a set of levels of technology maturity and the proposed modes of control for various platforms to be defined. The technical taxonomy and core RAS technologies related to military applications are briefly outlined in this section.

\subsection{Taxonomy}

The technology maturity of RAS technologies, applied to a platform and its attachment(s) is evaluated from the dyad of technology readiness level (TRL) and system readiness level (SRL). These TRL and SRL metrics are widely adopted by governments and research institutions. Their definitions can be found, e.g. a handbook by the Australian Defence Force (ADF) [8]. Both TRL and SRL vary from 1 to 9, with 1 corresponding to basic research and 9 corresponding to operationally-deployed systems. 
For judging the maturity level of a RAS platform in terms of systems integration, the level of autonomy (LoA) is also considered. Although not as widely recognised as TRL and SRL, the ten levels of autonomy suggested by Insaurralde and Lane [9] for unmanned military marine vehicles or the four LoA proposed by Finn and Scheding [10] for single-platform systems are useful indicators of technology maturity. Durst and Gray [11] suggested different levels in terms of interoperability, human robot interaction, information processing, control and monitoring. Their simpler non-contextual autonomy potential includes four LoAs ranging from LoA-0 for fully non-autonomous to LoA-3 for fully-autonomous platforms. For driverless vehicles, the five LoAs have been introduced by the Society of Automotive Engineers (SAE) International as a new standard [12]. In this paper, the concept of mode of control (MoC) for RAS-based platforms is proposed, focusing directly on the platform-centric control process for earthmoving. Here, the modes of control of a platform and its attachment are defined as follows:

- MoC 1 (Functional assist): In this mode the operator controls the machine and its attachments from the operator's cabin, with some RAS assistance to automate specific processes such as boom and bucket movements.

- MoC 2 (Teleoperation): In this mode the machine is teleoperated with functional assist, whereby the operator can control the machine either within the line of sight or via remote (on/off board) cameras and local monitors. A sub-category of teleoperation is remote control or open loop teleoperation.

- MoC 3 (Semi-autonomy): In this mode the machine operates semi-autonomously, whereby some specific functions are performed autonomously by the RAS installed on it.

- MoC 4 (Full autonomy): In this mode the machine is fully autonomous. That is, all operations and functions for task execution, including condition assessment and machine self-monitoring, are conducted autonomously without human intervention.

- MoC 5 (Cooperation): This mode of operation refers to a group of machines utilising MoC 2-4 that possess the capability of cooperation with each other and/or with humans and/or human-controlled machines to fulfill specific tasks.

In a broader sense, the level of autonomy for each ground-based construction platform can be grouped into two categories (i) remotely-controlled platforms in the open loop, and teleoperated platforms with closedloop control (MoC 2), and (ii) semi-autonomous and autonomous platforms (MoC 3-4).

\subsection{Core RAS technologies for army earthmoving}

Construction machines used in earthworks vary in application depending on their type, but often share a common configuration that includes a mobile platform and an attachment. Core technologies for autonomous operation of those machines are therefore similar to those of unmanned ground vehicles (UGVs) and can be presented in the block diagram shown in Fig. 1. In perception, the vehicle interprets its sensors to extract meaningful data. Operations of each platform require localization to determine its position in the environment. In navigation, the vehicle monitors and directs its movement to reach a destination from an initial location. To execute a RAS-based process, control is required from the lowest to higher levels, where the vehicle regulates its actuators to achieve a control objective. For cooperative operations, technologies relating to data communication, internet of things, networked robotics and coordination between platforms are required in the teleoperated, semiautonomous and autonomous modes.

\subsubsection{Perception}

Robotic perception represents the sensing and data processing required of an autonomous system to acquire and represent knowledge about its environment. That is, to obtain measurements using various appropriate sensors, to extract meaningful information from those measurements, and to represent the environment in the form of a model that can be updated and interrogated. 
There is a wide variety of sensors used in mobile robots. They are usually classified into internal (proprioceptive) and external (exteroceptive), or passive and active sensors. Some sensors provide extreme accuracy in well-controlled laboratory settings, while being subject to errors or even failure under realworld conditions. Other sensors provide narrow, high-precision data in a wide variety of settings. In general, sensors may be imperfect with errors of both systematic and random nature. Random errors, in particular, are associated with a level of uncertainty and are therefore often represented and manipulated by statistical methods. Statistical data from various sensors are processed to extract features such that an autonomous robot is able to determine its relationship to the environment with a known statistical variance despite measurement uncertainty. Line, range histogram, and features from other geometric kernels can be used in indoor environments. Visual appearance, texture, and colour-based features are more important for outdoor and complex environments. Computer vision and image processing technologies for object segregation and recognition are thus crucial for robotic perception.

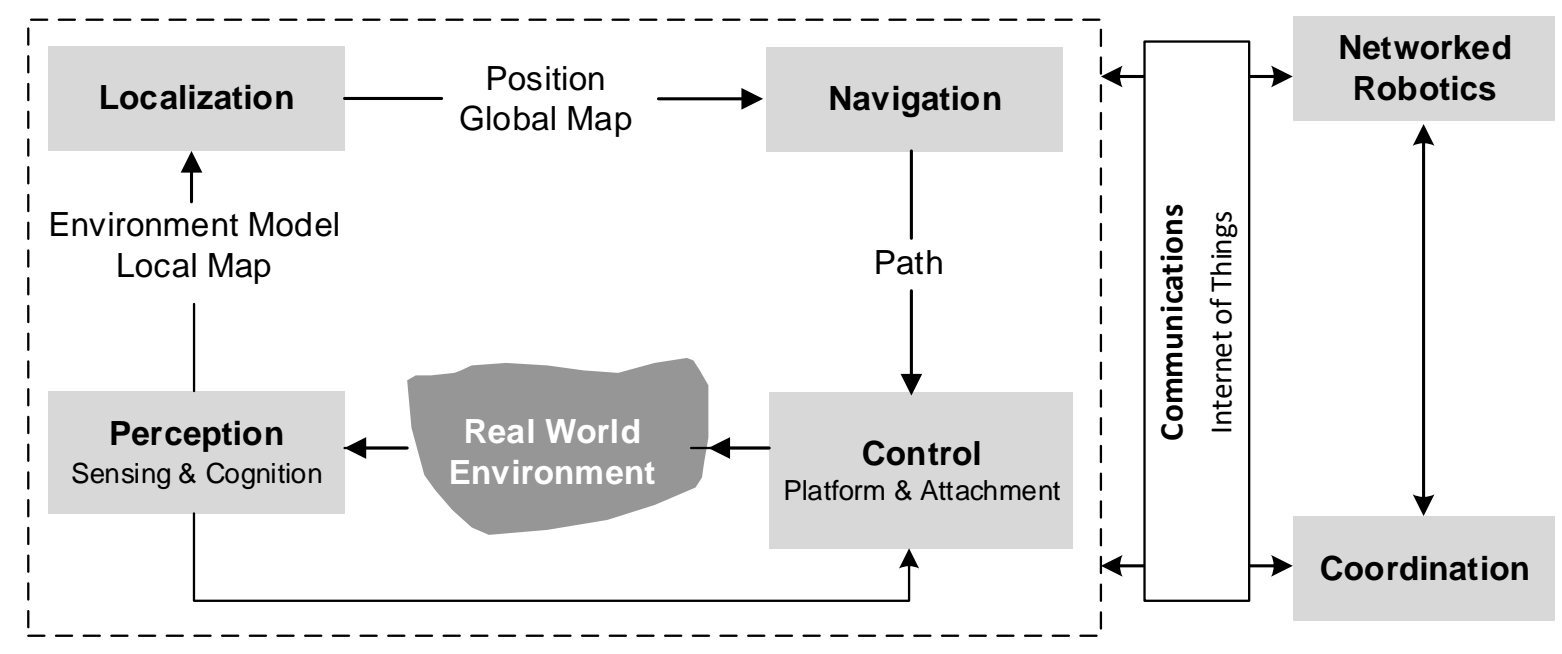

Figure 1: Core technologies for autonomous operation of construction machinery.

\subsubsection{Localization}

Three well-known approaches to localization include dead reckoning, absolute positioning, and sensor fusion. Dead reckoning, also referred to as relative positioning, is the estimation of a vehicle's position based on the speed and direction of travel and the elapsed time from its previous position. Absolute positioning employs measurements with respect to a 'global' frame of reference to locate the robot. Sensor fusion makes use of both relative and absolute measurements. Of interest is localization in two cases: with and without the availability of GPS data.

\section{a) GPS-based localization}

GPS-based localization is an absolute positioning method that provides a quick and efficient way to implement positioning modules for construction machines. The Original Equipment Manufacturer (OEM) offering factory-ready GPS bulldozers include Caterpillar, Deere and Komatsu while companies that make aftermarket kits that can be set up on most of commercial bulldozers for functional-assisted operation: Leica, Topcon and Trimble. The OEM Komatsu has released the PC210LCi-10 excavator, which features a revolutionary and fully factory-integrated 3-D GNSS machine control and guidance system.

Apart from traditional code-based GPS, the technique called real-time kinematic (RTK) positioning has recently been used to improve positioning accuracy to the centimetre level. This technique uses carrierbased ranging to provide ranges, and therefore absolute positions, that are orders of magnitude more precise than those available through code-based positioning. The basic concept of RTK is to eliminate commonmode errors between a base station and rover. RTK modules can be obtained from OEMs such as the u- 
blox (NEO-M8P GNSS module), Leica (GM30 GNSS receiver), or from Drotek (XXL RTK GPS base module).

\section{b) Localization in a GPS-denied environment}

Localization in a GPS-denied environment is based on the sensor fusion approach to take advantage of both relative and absolute position measurements. In relative positioning, encoder and IMU (inertial measurement unit) data are often fused. Encoder-based positioning works by integrating incremental position-change information over time. By using wheel encoders to count the number of revolutions of each wheel, the vehicle measures the distance and direction travelled and uses this information to estimate its present position from its previous position. An IMU can provide measurements of a body-specific linear acceleration, angular rate, and sometimes the magnetic field surrounding the body by using a combination of accelerometers, gyroscopes, and magnetometers. The relative positioning method is widely used owing to good short-term accuracy, high sampling rates, and low costs. Intermittent absolute position measurements are often used to reset the accumulated error after a certain period of time. On the other hand, absolute positioning can be used to locate a vehicle's position in a GPS-denied environment via geometric features obtained from a map-matching technique. For example, lines and points can represent walls and corners depending on the structure of the environment. The use of map matching and localization at the same time is referred to as simultaneous localization and mapping (SLAM), which has been an active research topic in robotics [13]. The main advantage of absolute position inputs to an inertial navigation system is their independence from previous estimations to avoid accumulated errors.

Fusing information from multiple sensors is essential for providing an accurate and complete picture of the environment. A number of fusion techniques have been proposed such as the central limit theorem, Kalman filtering, Bayesian networks, and Dempster-Shafer theory. In recent years, significant advances in localization have significantly improved its performance, in terms of accuracy and reliability, leading to the rapid development in driverless car technologies.

\subsubsection{Navigation and Control}

With imperfect and partial knowledge of its environment and a required goal position or time-series of positions, the navigation task requires a robotic vehicle to act based on its representation of the environment, in turn derived from sensor readings, to reach its goal positions efficiently and safely. Navigation is usually decomposed into two main tasks: path planning and obstacle avoidance. The task of path planning involves identifying a trajectory for the platform to reach the specified goal location. For obstacle avoidance, realtime sensing is used to adjust the trajectory of the robot to avoid collisions with other robotic platforms, stationary or moving objects. Various techniques and methods have been developed and field-tested for both path planning and obstacle avoidance tasks.

Automatic control is vital for a robotic platform to operate in any mode and with any level of autonomy. The control laws or algorithms for a platform, quite often multivariate, should be robust, tolerating internal and external perturbations and noise. Dependent upon the construction platform and its functional requirements, different control laws and algorithms have been implemented and validated with field tests. Control techniques and architecture [14] for construction machines have been well-developed with many advanced algorithms, both model-based and model-free. Field tests have proved that current technologies for platform control have almost reached the highest level of maturity.

\subsubsection{Communication and the IoT}

Communication is essential in military construction, and typically accomplished via wireless radio link or communications tether. In a harsh environment where radio frequency signal transmission is contraindicated, tethered communication provides an alternative using either fibre-optic cables or twistedpair copper wires. This is more common for construction platforms operating in an environment subject to congestion or jamming. On the other hand, wireless radio communications are generally limited to a certain frequency band (sometimes to a single frequency channel). Many platforms use unlicensed frequency bands 
(e.g. $2.4 \mathrm{GHz}$ ) that are susceptible to interference as other wireless systems. For military applications, communication radio systems need to be upgraded to new frequency bands to address interference concerns and the compatibility with counter radio-controlled improvised explosive device (RCIED) electronic warfare (CREW) systems. Higher frequency bands can support larger data rates required for real-time teleoperation video transmission, but the communications may be limited to line-of-sight (LOS) propagations

The Institute of Electrical and Electronics Engineers (IEEE) 802.11 standard is widely used for implementing wireless local area network (WLAN) computer communications adopted by some construction platforms. These over-the-air modulation techniques work well in multi-path environments and support high-rate data transmissions. Modern radios can transmit information to several target receivers simultaneously in a multi-cast process to enable collaborative interactions between platforms. Many small vehicles, by nature, have low antenna heights that make radio links susceptible to multipath fading, thereby drastically reducing their range and reliability. Current construction platforms use private communication links or networks. In military applications, a lost communication link will halt the machine's operations, exposing the operator to dangerous situations. Future autonomous capabilities, such as 'return to home' or 'move to safe location', may alleviate such issues associated with the communication loss. To create more interoperable networks, platform radios need to support multiple waveforms and span wider carrier frequency ranges. For this, enhanced software-defined radio (SDR) and smart antenna technologies are being developed to increase the multiband capability and range of radios. These technologies enable the radio to suppress interference or RF jamming while improving desired signal levels. As such, the cognitive radio (CR) technology can autonomously adapt to the RF environment by selecting the best modulation format and frequency for communication. Military construction platforms will be able to securely multicast information to troops and relay data between assets via mesh networks for improving non-line-of-sight communication within buildings and around obstacles without exposing the operator to danger.

With rapid growth of the telecommunication industry, vehicle-to-vehicle (V2V) and vehicle-toinfrastructure (V2I) communication will benefit defence operations in terms of force protection, saving personnel costs and reducing injuries. In the construction and infrastructure industry, the emerging Internet of Things (IoT), a paradigm manifesting the pervasive presence of a variety of objects possessing digital intelligence in a cyberphysical system [15], has found many applications in construction including remote operation, supply replenishment, tools tracking, equipment servicing and repair, usage monitoring, building information modelling, as well as power and fuel savings. In the military domain, IoT can be directly applied in a complex, multidimensional, highly dynamic and disruptive environment, e.g. a forward operating base, where commanders have to assess the situation accurately and promptly, gathering data from all possible sources to obtain rapidly the most complete and relevant picture (situation awareness) to make the best decision. Scenarios for use of IoT in warfare may include its applications to support tactical reconnaissance incorporating IoT technologies in force protection at bases as well as maritime and littoral environments, health and personnel monitoring, and equipment maintenance. Ground-based operations often depend on satellite communications, which may be vulnerable to hacking, leading to false coordinates. As such, challenges with real-time data processing and networked communications include (i) system reliability in interpreting the data collected to avoid missing vital information, and (ii) system security in maintaining high performance and operator's trust in transition to increased automation so as to overcome network imperfect conditions and avoid cyberattacks.

\section{Platform-centric development of earthmoving technologies}

The use of RAS technologies has played an important role in construction areas such as civil and building engineering, site planning, and construction logistics. In army applications, the earthmoving construction platforms of interest include excavators, bulldozers, front-end loaders, graders; and dump trucks. To achieve a comprehensive overview of recent advances in RAS technologies applied to the construction 
automation, particularly for military earthworks, it is essential to examine the application of RAS technologies to these platforms.

\subsection{Functional-assist platforms}

Functional-assist for construction platforms has reached technology maturity levels TRL 9 and SRL 9, with various modules implemented in commercial products. In earthmoving, sensory deficits will retard task execution since the operator will take a longer time to adjust a setpoint or desired trajectory. As such, work efficiency in teleoperation of construction platforms can be improved by achieving higher accuracies in the attachment control through functionally-assisted movements. With the dual aims of enhancing work capacity and obtaining higher task efficiency, functionally-assisted manipulation has been designed to complement human operations. Experiments showed that the trajectory assistance improved bucket pathfollowing accuracy while maintained a feeling of manual control during teleoperation. The accumulated cycle time was reduced, and overall work efficiency was significantly improved.

In a highway construction project in Hokkaido, Japan, the blade control system providing support to the grader operator was reported to greatly improve the accuracy and productivity [16]. Likewise, an automatic grade-assist option has been added by the OEM Caterpillar to the 'Grade System' control panel of its CAT 323FL excavator. The grade-assist system enables operators can improve the work efficiency up to nearly $50 \%$ with respect to manual grading. The operator provides an entry for the target depth and the grade control system takes control of the bucket when its edge is within $10 \mathrm{~cm}$ of the target, locks onto the grade, and automatically adjusts the boom up/down and bucket in/out movements. The operator then controls the stick-in speed using a single lever to achieve a grade accuracy of 2 to 3 centimetres.

The Komatsu PC210LCi-10 intelligent machine control excavator with functional-assist capabilities was designed to allow operators to focus on moving material efficiently, without having to worry about digging too deep or damaging the target surface. The system can result in more than a $60 \%$ improvement in work efficiency when compared with conventional construction processes [17]. Similar functional-assist systems were also installed for a bulldozer to provide 3-D design surfacing and real-time blade edge positioning in relation to the machine, whereby accurate knowledge of the blade edge position and movement allows the operator to complete assigned tasks with higher speeds.

\subsection{Excavators}

With the serial-link structure as of a robotic arm, the excavator is the most popular platform used in earthworks that applies the RAS technologies in achieving a higher level of autonomy of the bucket or a front attachment, the upper structure including cabin and equipment, and/or the undercarriage or base. Depending on the rated engine power, excavators can be categorized into light, medium and heavy types which are all available for military earthworks.

\subsubsection{Remotely-controlled and teleoperated excavators}

Teleoperated excavators involve a method to control at least the motion of the bucket and machine travel from some distance away. An early prototype was developed in 1992 by Burks et al. [18]. The studies, funded by the US Army, aimed to find principles for teleoperating excavators for retrieving unexploded ordnance or radioactive waste. The use of a "spontaneous hand controller" coupled with a graphical user interface reduced the difficulty of handling tasks and eliminated hours of training. To evaluate the feasibility of removing personnel from the vehicle during high-risk excavation tasks, the development was initiated to evaluate performance capabilities of the small emplacement excavator (SEE) under tele-robotic control. The teleoperated SEE features teleoperated driving, a tele-robotic backhoe with four degrees-of-freedom, and a teleoperated front loader with two degrees-of-freedom on the bucket. Remote capabilities include driving (forward, reverse, brake, steering), power take-off engagement to enable digging modes, deploying stabilizers, excavation and computer system booting. The system was operated via an intuitive hand controller at a remotely-located portable, suitcase-size base station and could be operated manually using a 
customized electromechanical actuator package to replace the conventional mechanical levers and foot pedals. Demonstrations showed that the system was suitable for retrieving unexploded ordnance.

Various subsystems and prototypes for teleoperated excavation corresponding to TRL 3-6 have been reported in the literature. Teleoperation involving telegrasping sensory perception, based on master-slave teleoperation of a grapple attached to an excavator, was carried out using a joystick as the master and the machine as the slave [19]. The proposed control system significantly improved the slow grasping of a soft object by improving the sense of grasping through force feedback. Precise grasping was also tested by using auditory, vision-based feedback or virtual reality along with force feedback. Kim et al. [20] studied the control of an excavator using the movements of the human arm to give commands to manipulate the excavator operations via haptic devices and visual feedback. In [21], a remotely-controlled pneumatic robotic system is developed to replace a human operator. The effectiveness of the remotely-controlled operations conducted at a local construction site was determined by an increase in working efficiency of approximately $50 \%$, compared to the direct manual operation of the excavator. The concept of dual-arm double front construction machinery was demonstrated in [22] for demolition work using teleoperated manipulators and a grasping mechanism, each with six degrees of freedom, five single-rod hydraulic cylinders and one hydraulic motor. From results published and laboratory demonstrations, developments in those remotely-controlled and teleoperated excavators are evaluated at TRL 6 / SRL 6 for their technology maturity.

The first practical disaster recovery work using teleoperated equipment for post-volcanic and earthquake disaster applications was tested in Japan after the disastrous eruption of Mount Unzen in 1994 using a construction technique known as 'Sabo', which can dig and safely carry away rubbles [23]. Sabo is a Japanese construction technique that involves the construction of barriers and dikes that ensures public safety from flows of disaster debris. The operators received real-time video images and their commands were transmitted wirelessly. The restoration following this volcanic eruption and another one at Mount Usu in 2000 marked the first large-scale unmanned post-disaster recovery construction work. Later, in March 2011, remotely-controlled and teleoperated hydraulic excavators and dump trucks were called in for the crucial clean-up of debris at the Fukushima nuclear power plant after the Great East Japan earthquake [24].

Since the early prototype [18], numerous studies have been conducted to develop components and subsystems for remotely-controlled and teleoperated platforms such as communications protocols, kinematic and dynamic models [25], control and planning [26], soil-tool interaction models [27], simulation and navigation [28]. Apart from academic R\&D activities, companies such as ASI Robots Inc. have developed platform-independent systems with controllers and sensors that can be integrated into existing vehicles for teleoperation. Other OEMs like Caterpillar and Komatsu have introduced their in-house remotely-controlled and teleoperated machines. In the military domain, remotely-controlled ground vehicles have been deployed for high risk tasks such as mine clearance. These include, for example, the CAT M160, a teleoperated light flail system designed with line-of-sight communications for unmanned mine clearing missions, and the A2 PackBot, a family of unmanned ground vehicles providing soldiers with remote inspection and manipulation capabilities for combat engineer missions or those involving explosive or hazardous materials and reconnaissance.

For teleoperated excavators, the technology maturity has reached TRL 7-8 and SRL 6-7. The progress in developing remotely-controlled and teleoperated excavators in the past 25 years can be depicted by Fig. 2(a). Over the next five years it is envisaged that augmented reality (AR), GPS-based and laser-based localisation, ground scanning and warning sensor technologies will be developed with field tests conducted on actual platforms to improve the range and performance of teleoperated excavators, together with the necessary development of human-machine interaction subsystems. In the next ten years, commercial-offthe-shelf (COTS) platforms are expected to be available in the market. For example, Volvo's GaiaX concept model [29] will have the capability to carry out most applications remotely using an augmented reality tablet computer. Excavators in the next fifteen years will be able to cooperate with other platforms such as bulldozers and dump trucks for complicated construction tasks such as unsealed road construction. 
In defence, application kits such as the Modular Robotic Control System (MRCS) and the Appliqué Robotics Kit (ARK) have been successfully integrated into earthmoving platforms since 2006 for teleoperation of such construction tasks as excavating, lifting/loading, stripping, levelling, and stockpiling in military applications [30]. Recently, DRS Technologies Inc. has teamed with Autonomous Solutions Inc. (ASI) to build autonomous systems for US Army route-clearance vehicles [31]. The companies aim to provide the US Army with the option to remotely operate Army-legacy high mobility engineer excavator (HMEE) Type I vehicles in the teleoperated mode. It is also foreshadowed that military-off-the-shelf (MOTS) products will be available around 2030 judging on active research in this field as well as the high demand for protecting troops from roadside explosives. Figure 2(b) shows an estimated projection on the future development of teleoperated excavators presented subsequently in epoch charts for five, ten, and fifteen-year periods.

\section{TRL and SRL for teleoperated excavators}

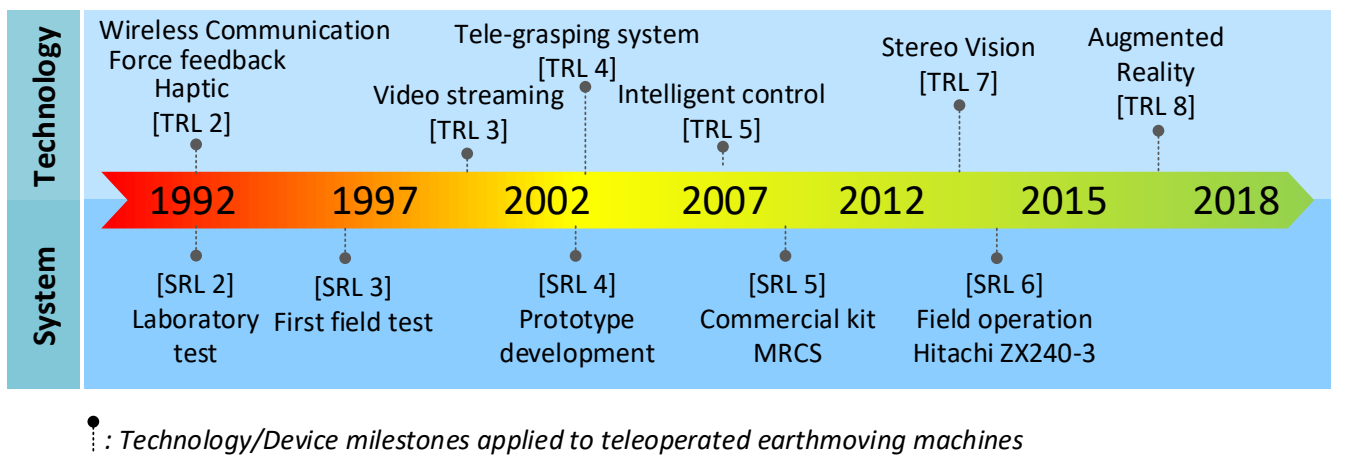

(a) Progress to date

\section{TRL and SRL for teleoperated excavators}

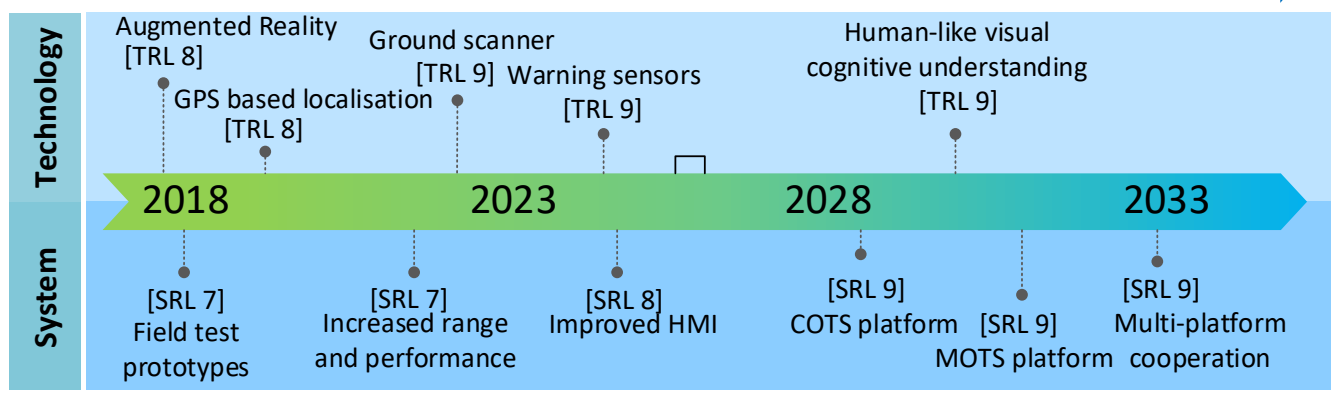

: Technology/Device milestones applied to teleoperated excavators

(b) Future projection

Figure 2. Development of remotely-controlled and teleoperated excavators.

\subsubsection{Semi-autonomous and autonomous excavators}

Autonomous excavation refers to digging operations without direct input from a human operator. It will involve an automatic control system that is able autonomously to conduct a planned dig and is responsive to bucket-soil interaction forces arising from the excavation process in real time. Studies in this direction started in 1986 with a robotic excavator named REX [32], aimed to identify early critical issues in the autonomous excavation, then to trial and test feasible solutions for it. The development of an automated excavation system is usually based on a dynamic model that describes the system motion. Budny et al. [33] 
dealt with the kinematics of the excavation process, postulating a unique relationship between the bucket motion and the action of the actuators. Dynamic models of the excavator were developed by applying the Newton-Euler equations to each link in succession, or the Lagrangian formulation, and using the inverse kinematic equations to determine the joint angles and the actuator lengths corresponding to a specific position and orientation of the bucket [25]. Recent research by Zhou et al. (2015) includes a surfacing method where the operation functions are modelled through analysis of deterministic processes and trajectories of the working tools [34]. Modelling of the operation functions will promote application of unmanned excavators and provide experience for the advanced control of other unmanned construction machines.

Interactions between construction tools and soil represent are important for autonomous operation of an excavator. Digging forces arising out of the soil reaction to the driving tool are time-varying and complicated since small variations in soil properties can cause significant changes in its static and dynamic behaviour. Learning and reacting models have been proposed to sufficiently predict the tool-soil interaction sufficiently well [35]. Soil parameter estimation enables prediction of interaction forces by changing tool parameters such as the depth of cut, the attack angle of the tool, and digging strategies. To this end, efficient methods are required for soil parameter estimation. Song and Koivo [36] developed a multilayer neural network method in the control system to perform a rudimentary trajectory generation for an excavator end effector while a fuzzy logic system was proposed in [37], requiring no a priori knowledge of soil conditions. While different tool-soil interaction models exist, soil behaviour by nature is complex and the variation of some parameters can greatly alter the soil conditions. Sensors can therefore provide information to compensate for such variations for robust control of the excavation process [38].

Control is essential for the proper operation of any automated excavation systems. For controlling a simple backhoe arm, an intelligent control system was developed to apply a force over its operating envelope to autonomously dig in hard ground [39]. The software developed to deal with highly varying soil conditions was then implemented in a real excavator. Force and position control during digging was studied in [40] for a robotic excavator via tracking the piston position and ram force of each hydraulic cylinder for the boom, arm, and bucket axes. The impedance control of a hydraulically-actuated robotic excavator was proposed in Ha et al. [26] on a Komatsu platform to control the dynamic relationship between the reaction force and the bucket tip displacement. Closed-loop control performance for robotic excavators can be justified also in dealing with the system sensitivity to parameter variations, for example, oil temperature, working time and number of cycles.

In high-level control, excavation tasks are executed in the semiautonomous/autonomous mode of control via a planning system. For example, Matsuike et al. developed a control system, in support of deep excavation, in which diaphragm-walls were accurately formed with errors less than 30-50 mm [41]. In many excavation tasks, such as trenching or excavation for footings, a task can be decomposed into multiple subtasks corresponding to the trajectory control of the bucket tip. Based on the exact kinematic transformation from boom state space to Cartesian workspace variables, a control procedure was proposed by linking boom variables to reduce the inputs to only one that allows to determine piles on the ground, from which numerical models representing the process could be developed. A robotic excavator was developed in [42] for demonstrating autonomous execution of some typical excavation tasks in construction. In another approach, Maeda [35] dealt with disturbances arising from the material removal process by proposing iterative learning control with a learning function as a predictive controller for autonomous excavation. The same hydraulic mini-excavator developed was used as a testbed to evaluate experimentally the performance of the conventional iterative learning controller against a robust controller.

From the early prototype REX [32], full-scale autonomous excavation was later pioneered by Stenz et al. [43] on a 21-ton robotic excavator with performance demonstrated in the task of loading trucks with soft soils at the same speed as of a skilful human operator. The test rig had two scanning laser rangefinders which recognised the truck, measured the soil volume in the shovel and in the truck, as well as detecting obstacles in the workspace. The sensors helped the excavator modify both its digging and dumping plans to fit the soil settlement in real time. Gain scheduling was utilised in [44] to regulate the highly nonlinear 
joint dynamics for excavation tasks that require accurate excavation such as finishing of ditches and levelling a crushed stone base drainage ditches over a distance of eight kilometres. A vision-based control system that considered track slip of an excavator was developed in [45], including several controllers that could be collaboratively operated to move the mobile platform from a starting position to a target location. The testing results showed that the differences between the desired trajectory resulting from the trench shape and the trajectory of the actual movements of the bucket tip can be kept within $10 \mathrm{~cm}$. The system was also able to complete the autonomous loading of a crawler dump truck. Acquisition systems for 3-D information of the execution process, human-machine interface, and extensive automatic control strategies have been developed to improve accurate path-tracking and slippage control for robotic excavation. In a recent project, Volvo prototyped the EW 180B excavator as part of the THOR (terraforming heavy outdoor robot) autonomous excavator project that aims to develop a construction machine without an operator [46]. Control software was developed to allow the bucket to autonomously move to a given target position without human input. In addition, two concepts have been verified for future developments: hardwaresupported collision prevention during excavation, and the utilization of $\mathrm{iB} 2 \mathrm{C}$, a behaviour-based control system developed by Volvo's Robotics Research Lab, for workspace limitation and collision avoidance.

From the literature and industrial observations, the technology maturity for autonomous excavators has reached TRL 6-8 and SRL 6-7 in a well-structured of a civil construction site environment as shown in Fig. 3(a) with our projection per 5-year epoch for the development of autonomous excavators presented in Fig. 3(b). It is in prediction that COTS semi-autonomous products at SRL 7 will be ready by 2033 and made available with cooperation capability within the coming decade.

TRL and SRL for semi-autonomous/autonomous excavators

\begin{tabular}{|c|c|c|c|c|c|c|c|}
\hline \multirow[t]{2}{*}{ 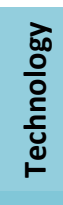 } & $\begin{array}{l}\text { Sonar sensor } \\
\text { [TRL 2] }\end{array}$ & \multicolumn{2}{|c|}{$\begin{array}{l}\text { Scanning laser } \\
\text { rangefinders } \\
\text { [TRL 3] }\end{array}$} & $\begin{array}{r}\text { 3D } \\
\text { Intellig } \\
\text { [T }\end{array}$ & $\begin{array}{l}\text { ironment } \\
\text { RL 7] } \\
\text { control } \\
6]\end{array}$ & \multicolumn{2}{|c|}{$\begin{array}{c}\text { Hardware-supported } \\
\text { collision prevention } \\
\text { [TRL 8] }\end{array}$} \\
\hline & 1986 & 1992 & 1998 & 2004 & 2010 & 2014 & 2018 \\
\hline 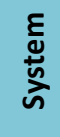 & $\begin{array}{l}\text { [SRL 2] } \\
\text { REX } \\
\text { prototype }\end{array}$ & Aut & $\begin{array}{l}\text { 3] } \\
\text { nous } \\
\text { ng }\end{array}$ & $\begin{array}{r}\text { [SRI } \\
\text { Autonomol } \\
\text { pro }\end{array}$ & $e^{x c a v a t o r}$ & $\begin{array}{r}\text { [SR } \\
\text { Autonomol } \\
\mathrm{TH}\end{array}$ & avator \\
\hline
\end{tabular}

:: Platform System / Technology milestones applied to autonomous excavators

(a) Progress to date

TRL and SRL for semi-autonomous/autonomous excavators

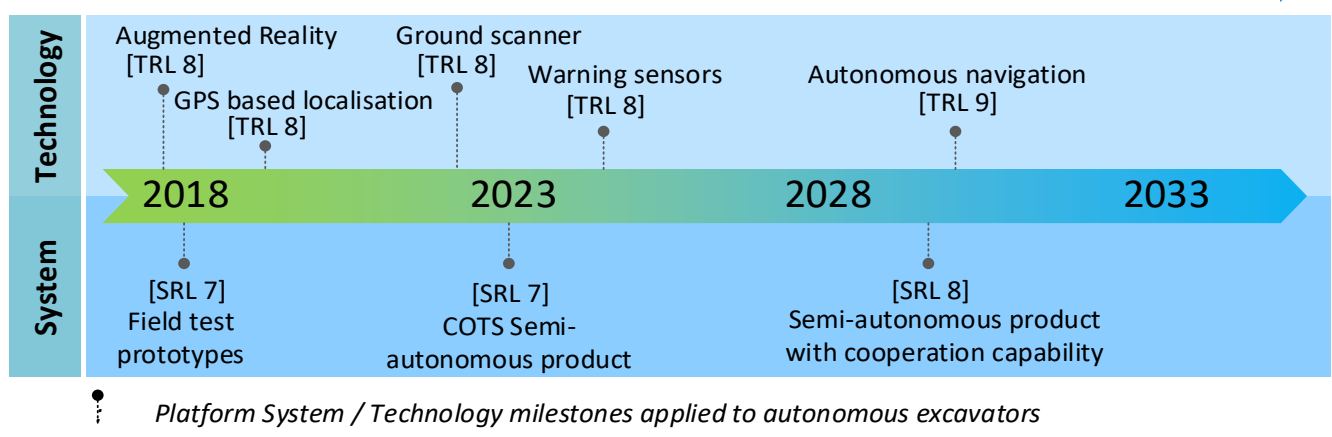

(b) Future projection

Figure 3. Development of semi-autonomous and autonomous excavators. 


\subsection{Bulldozers}

A bulldozer is an important platform in military earthmoving as it is a robust, powerful tracked machine that can provide exceptional traction and mobility on a variety of difficult terrains. In defence, bulldozers employed for combat engineering are often fitted protection armour while combat engineering vehicles are usually equipped with bulldozers blades.

\subsubsection{Teleoperated bulldozers}

As with excavators, a number of teleoperated bulldozers with different levels of technology maturity have been developed for earthmoving tasks. Dating back to 1995, a 'tele-earthwork system' [18] for removing volcanic rocks emanating from eruptions of Mount Fugen, Japan, was developed with an operating range of up to $1.8 \mathrm{~km}$ and field work being managed through global multimedia including satellite communications. A teleoperated system was also developed in the Pioneer Project funded by the US Department of Energy and National Aeronautics and Space Administration (NASA) as a specialized, tethered, bulldozer-like robot to inspect Unit 4 at the Chernobyl nuclear power plant. The robot was equipped with stereo vision for real-time 3-D mapping, a core-drilling and sampling apparatus, and an array of radiation measuring and other sensors [47].

Remote control of bulldozers used in coal stockpiles was reported in [48] on the feasibility of the technologies applied to a bulldozer. The machine was operated either via remote control or by an on-board operator. Other features included an emergency stop system, automatic blade control during loading, danger alerts using the GPS-based CAES Ultra system, remote diagnostics, and automatic braking. Pan-tilt cameras that used operator head movements to control the cameras were investigated. The system consisted of the operator wearing a pair of goggles while operating the bulldozer via the remote-control pendant. A number of experiments were conducted in which the operator was able to operate the bulldozer safely and efficiently from a remote position. Recently, a teleoperated bulldozer with force feedback [49] was introduced by using sensors attached to the blade and transmitting data to the control system. Cameras were installed for visual feedback within and on the roof of the operator cabinet of the remotely-controlled bulldozer-type robot. Experimental results showed that providing force feedback to the operator significantly reduced the operation time compared with when only visual information was displayed on the operating screen.

In industrial applications, ASI Robots Inc. introduced a system called NAV that incorporated controllers and sensors that could be integrated into existing vehicles for teleoperation. The system has been tested in the field under real operating conditions and subsequently commercialized [50]. A Caterpillar product called 'Cat Command for Dozing' can support remote, line-of-sight operation of a bulldozer using a portable console. The system is fully integrated with auxiliary components, systems and electronic control modules (ECMs) used on the D10T and D11T bulldozers, such as Autocarry and Auto Blade Assist. It has the ability to use avoidance zones set up in the Caterpillar Terrain guidance tool. First used in mining in 2011, the Command for Dozing system has logged more than 25,000 hours of teleoperation time with more features being added such as real-time audio and video feeds for operators. The latest system allows one operator to control up to three machines at one time from a remote location.

Progress in developing remotely-controlled and teleoperated bulldozers in terms of Platform System and Technology can be summarized and projected as shown in Fig. 4. With COTS products already available by 2020 , it is projected that future teleoperated bulldozers will achieve improved performance through the addition of semi-autonomous hybrid control capabilities.

\subsubsection{Semi-autonomous and autonomous bulldozers}

Studies on autonomous bulldozers began several decades ago, similarly to excavators. Muro [51] introduced an automatically-controlled system for maximising the productivity of a bulldozer running on weak terrain, whereby a microcomputer was used to obtain information on terrain properties and vehicle states to facilitate achieving the optimum drawbar-pull and slip ratios when working. Since then, various studies have been conducted focusing on different technologies for autonomous operation such as 
modelling and control, position and pose estimation, machine-soil interaction, navigation systems, simulation, and pilot system tests.

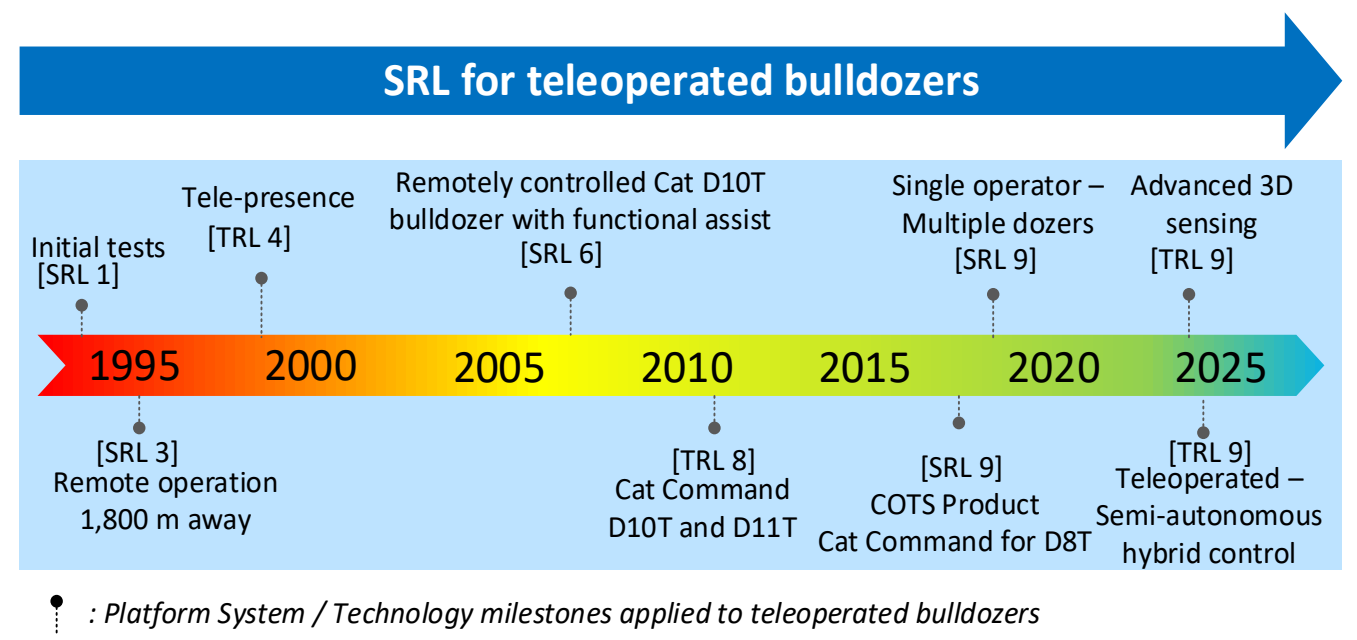

Figure 4. Progress in developing remotely-controlled and teleoperated bulldozers.

Modelling and control remain essential for the development of autonomous bulldozers. Platform parameter estimation and validation were completed using experimental data from a scale model bulldozer [52] with average normalized root-mean-square prediction errors of $0.9 \%, 3.1 \%$ and $4.4 \%$ for one-step-, five-step- and ten-step-ahead prediction horizons, respectively. The model can be used for the future development of model-based optimal bulldozing control. In terms of track tension and sinkage relations, the effective tractive effort increases monotonically with increasing track tension while the total amount of sinkage at the rear sprocket decreases remarkably, and hence an automated tension control system would be required to adjust the bulldozer's track tension according to the underlying terrain. A simple control system was introduced to control a bulldozer blade [53], wherein the force acting on the blade was modelled and utilized in an adaptive control strategy for the blade.

In the soil blade interaction, the edge of the bulldozer blade first penetrates the soil up to a certain depth, then the bulldozer starts cutting, shearing and pushing the soil. During this contact phase, the blade experiences enormous resistance owing to friction, cohesion and adhesion between the blade and soil, and the soil and ground [54]. The force acting on the blade varies in a complicated manner that may negatively impact the bulldozer performance. It is therefore important to understand the soil-blade interaction in both bulldozer design and operation phases. The problem of soil resistance or 'draft force' can be tackled either experimentally, or by developing analytical models and using numerical methods. Significant R\&D effort has been devoted to model the soil-blade interaction within both academia and industry.

Given a dynamic vehicle model, soil-blade interaction model and control techniques, studies in higherlevel bulldozer control such as planning and navigation have been conducted. Control of the platform driving force, tracking and navigation are essential for improving the performance of the bulldozer drive system and its capability of executing robotic tasks. For tracking, 3-D coordinates can be determined by using a time-of-flight laser range finder and angle encoders as a measuring head, together with optical reflectors attached to the machine. In [55], a guidance system was developed for bulldozers based on sensor fusion of an inertial measurement unit integrated with two GPS receivers. This combination provided accurate estimates of the pose and position of the bulldozer blade, providing feedback for the navigation system.

The early development of autonomous bulldozer prototypes was motivated by the US lunar exploration project in which the goal was to construct a permanently manned lunar base relying on the use of large 
bulldozer-like vehicles to be driven by an astronaut, either locally or under teleoperation. Prototypical bulldozer-rovers were also developed for the task of "dish up the dirt" and "pack it in" on Mars using 3.6 $\mathrm{kg}$ bulldozer-rovers having arms with a tiny scoop to dig and dump soil into an overhead bucket. These toy bulldozers are to be upgraded in the space programs with a lightweight bulldozer blade prototype designed and built in conjunction with the NASA Chariot lunar mobility platform [56] to evaluate the autonomy capability and excavation performance, and to study excavation behaviour in a simulated lunar geotechnical environment.

ASI Robots Inc. has developed some platform-independent computer and sensor subsystems that can be integrated into an existing bulldozer to facilitate autonomous operations used in industrial applications. They consist of the on-board computer and communications system NAVTM, the obstacle detection and avoidance module Vantage ${ }^{\mathrm{TM}}$, and the Mobius ${ }^{\mathrm{TM}}$ command and control software [50] to form a "universal automation solution for vehicles of different shapes, sizes, and applications". Autonomous bulldozers have also received much research interest from Caterpillar with several projects being conducted. For example, the Caterpillar Command for Dozing framework can simulate the movement of material under the action of a bulldozer and computes a push sequence for efficient material movement, and hence, demonstrate feasibility of semi-autonomous pivot-push bulldozing.

For military use, bulldozer blades can be optionally fitted to platforms including, such as artillery tractors of Type 73 or M8 Tractor. Dozer blades can also be mounted on main battle tanks, where it can be used to clear antitank obstacles, mines, and dig improvised shelters. Combat applications for dozer blades include clearing battlefield obstacles and preparing fire positions. Bulldozers employed for combat engineering roles are often fitted with armour to protect the driver from small arms fire and debris, enabling bulldozers to operate in combat zones. The Israeli Army Engineering Corps have completed an extensive project to equip unmanned bulldozers, shown in Fig. 5, to carry out some autonomous tasks for earthworks, clearing terrain obstacles, opening routes and detonating explosive charges [57].

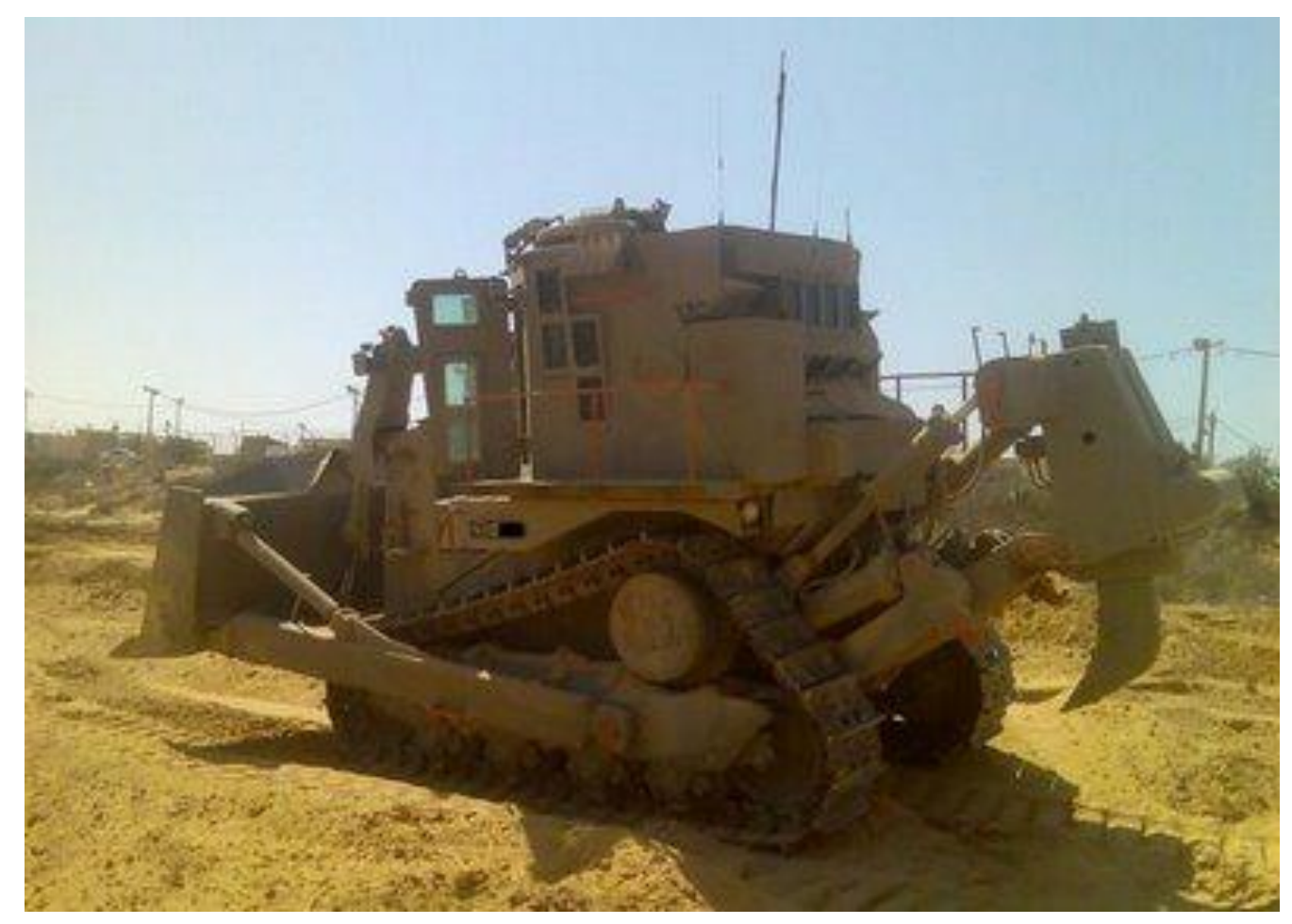

Figure 5. Robotic bulldozer used by Israel Defence Forces [57]. 
The technology maturity for semi-autonomous bulldozers in a structured environment has reached TRL 6-8 and SRL 6-7. With the current very strong demand from the market it is predicted that semiautonomous bulldozers will be available commercially within the next five years while fully autonomousbulldozers will take longer considering their typical unstructured operating environments. Figure 6 shows the projected development of semiautonomous/autonomous bulldozers.

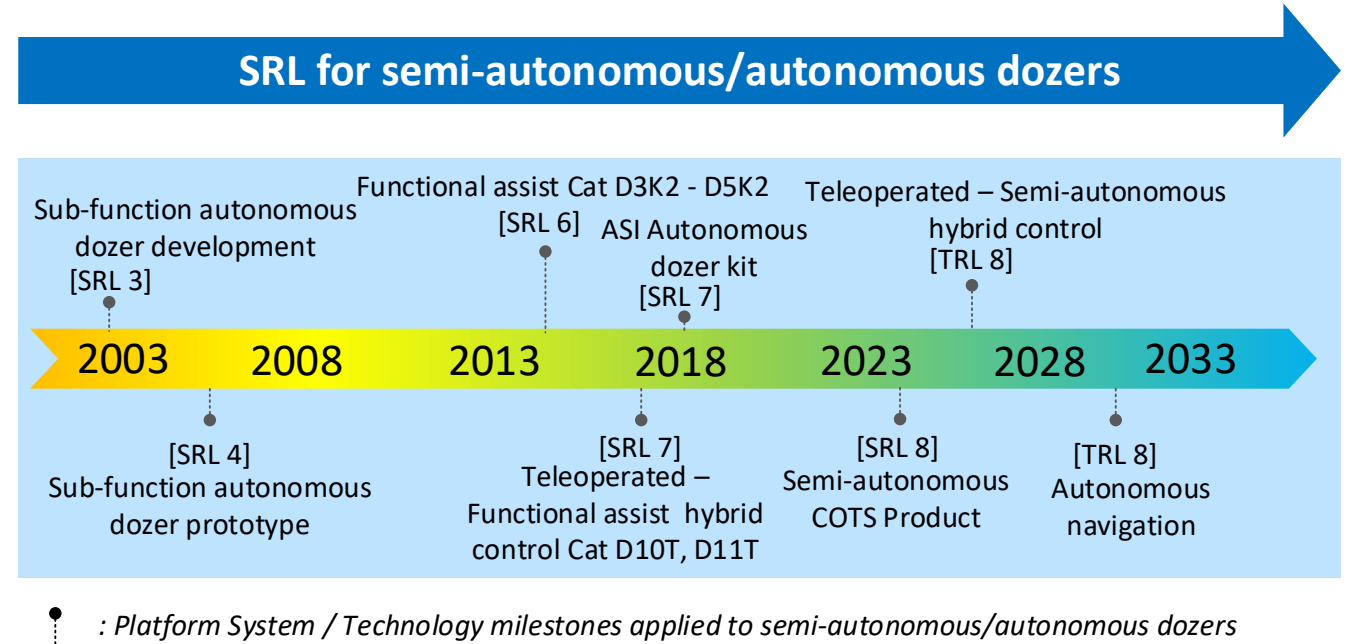

Figure 6. Projected development of autonomous bulldozers.

\subsection{Loaders}

Front-end loaders are commonly-used in military earthwork applications that typically require to move stockpiled granular material from ground level to deposit into an awaiting dump truck or an open excavation site nearby.

\subsubsection{Remotely-controlled and teleoperated loaders}

Robotic front-end loaders are considered as an integrated system of hydraulic, mechanical and electronic subsystems. Being widely used on construction sites, these machines have received much research interest. Since 1990's, the study on control and planning of frond-end loaders has become active. With computer control, the linkages between positioning, tracking and trajectory following can be established in either Cartesian or angular coordinate motion of the platform. The joystick implementation was also modified to better manipulate pistons and buckets and thus improve the level of autonomy. Further research and studies have progressed since that time on various aspects of loaders from subsystem enhancement to sensor integration for autonomous navigation and task execution.

For remote control and teleoperation of loaders, a commercial product of Applied Research Associates Inc. named a modular robotic control system (MRCS) was introduced for the teleoperation of tracked vehicles and tracked construction equipment [29]. The MRCS is a stand-alone unit consisting of three main elements, namely (i) a man-portable operator control station (OCS), (ii) a platform control component (PCC), and (iii) a wireless data and video link. The MRCS has been installed into a teleoperated robotic platforms for humanitarian demining such as the Nemesis HD for ground clearance and landmine detection [58]. It was also implemented on the Caterpillar 924G Bucket Loader used by the US Marine Corps, as depicted in Fig. 7(a), for military earthworks in which the soldier operator can be removed from hazardous areas [30]. Another commercial-off-the-shelf robotic kit, the Appliqué Robotics Kit (ARK), was also designed to allow for the modification of existing construction equipment, converting it into a remotelycontrolled platform. The ARK, integrated to the US Army HMEE III, a loader/backhoe by the US Army, was useful in teleoperated excavation of small emplacements, materials handling, and general earthmoving tasks, as shown in Fig. 7(b) [30]. Experimental results showed that this unmanned system was suitable for the operational use in support of hasty route clearance operations. 
For teleoperated operations, a case study of using teleoperated equipment was introduced in [59], wherein a permeable infiltration unit (PIU), or sand cover with various integrated systems, was constructed to contain and treat the 'Old O-Field' chemical munitions landfill at the US Army Garrison, Aberdeen Proving Ground in Maryland, USA. A teleoperated Caterpillar D-6H bulldozer and a Caterpillar 320L loader developed by Lockheed Martin were used for the placement of the initial sand layer. Teleoperation allowed the equipment operators to keep approximately $1.6 \mathrm{~km}$ away from the most hazardous location. After three months of placing the sand layer, the high risk of working on such sites as Old O-Field was considered as controlled and subsequently reduced owing to the placement of the sand layer. In mining, underground LHD loaders can be integrated with the Caterpillar 'Cat Command' framework to be teleoperated with the main remote operator station for the loaders being connected to the equipment via fibre optic cable.

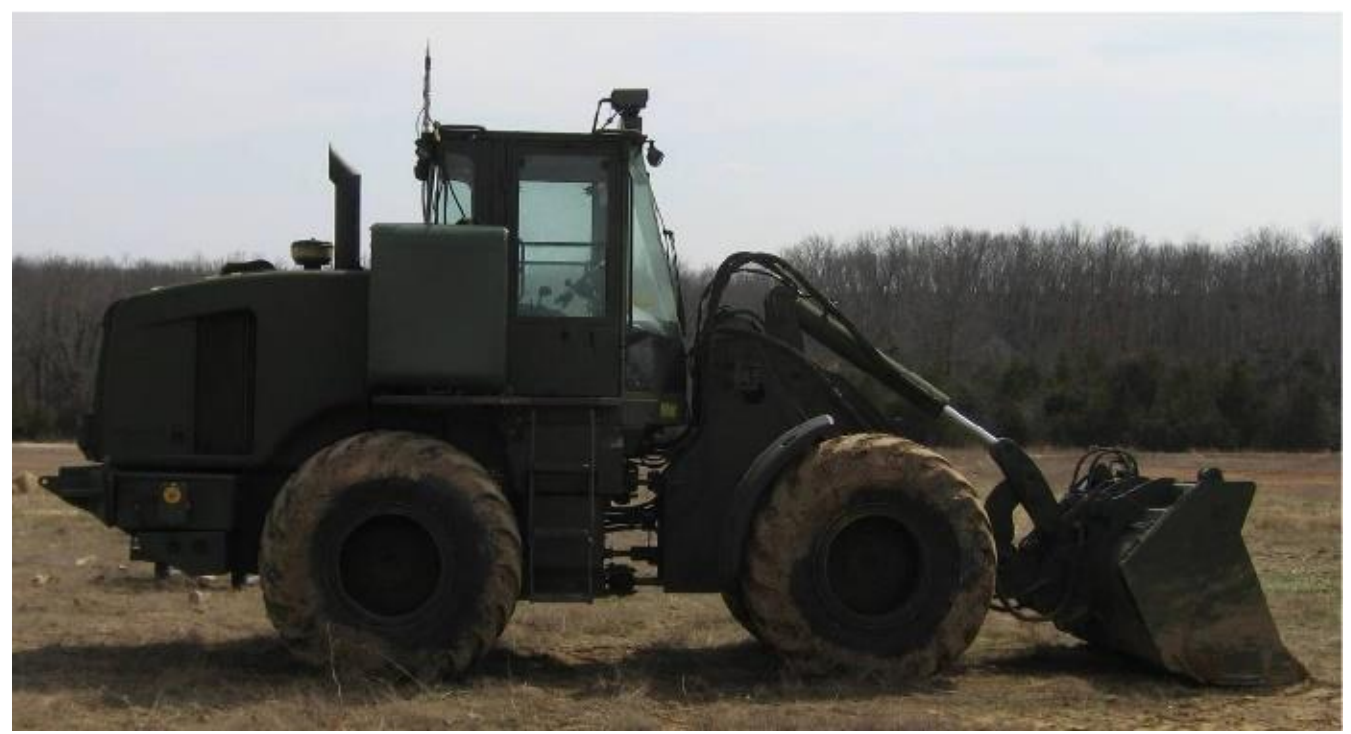

(a) Caterpillar 924G with MRCS [30]

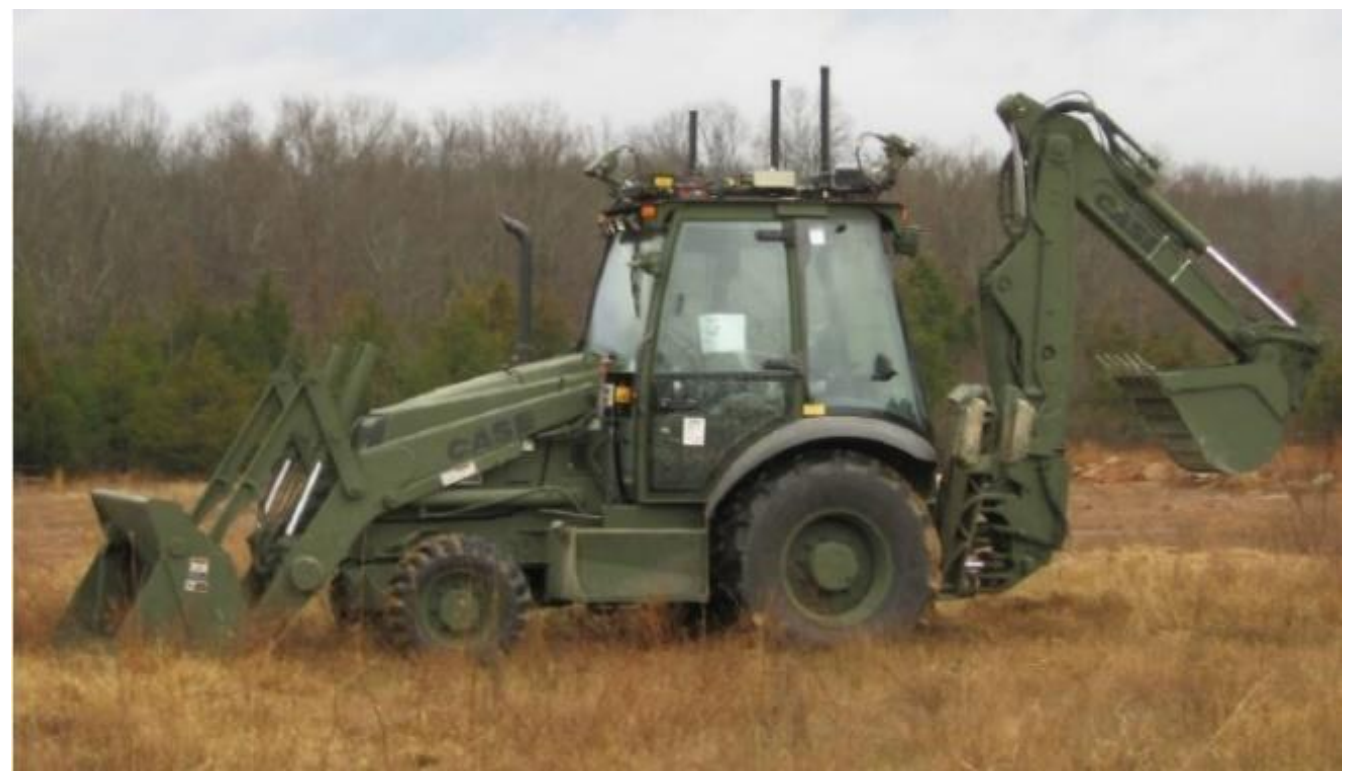

(b) HMEE III with ARK [30].

Figure 7. Robotic loader in military applications 
More recently, the Cat Command framework enabled line-of-sight remote control of Caterpillar 988K wheel loaders. The system reduces the risk of injury and enables production to continue by allowing safe operation of the loader in potentially hazardous environments. Caterpillar 'Command for Loading' is available as a retrofit kit for $988 \mathrm{~K}$ machines operating on the field. In another project, Hard-Line Inc. introduced a commercial product named Hard-Line's Teleop ${ }^{\mathrm{TM}}$ Loader Teleremote Control System that allowed tele-operation of loaders and other machinery from a remote-control station. The system was developed as an application kit that can be installed on an existing loader platform.

It can be seen that COTS loaders with remote control function within line-of-sight such as the Caterpillar 988K have been available in the market. Other commercial application kits such as MRCS, ARK and HardLine's Teleop could be implemented to turn loaders into teleoperated platforms. Field tests of teleoperated loaders have been successfully conducted by Caterpillar in the mining industry. More recently, the system readiness level of remotely controlled and teleoperated loaders is therefore estimated to be at SRL 8-9. Over the next five years it is envisaged that COTS platforms for teleoperated loaders will be available, and not long after that, loaders with a hybrid teleoperation and semi-autonomous control mode will also become commercially available. A projection of the development of remotely-controlled and teleoperated loaders could therefore be suggested as shown in Fig. 8 .

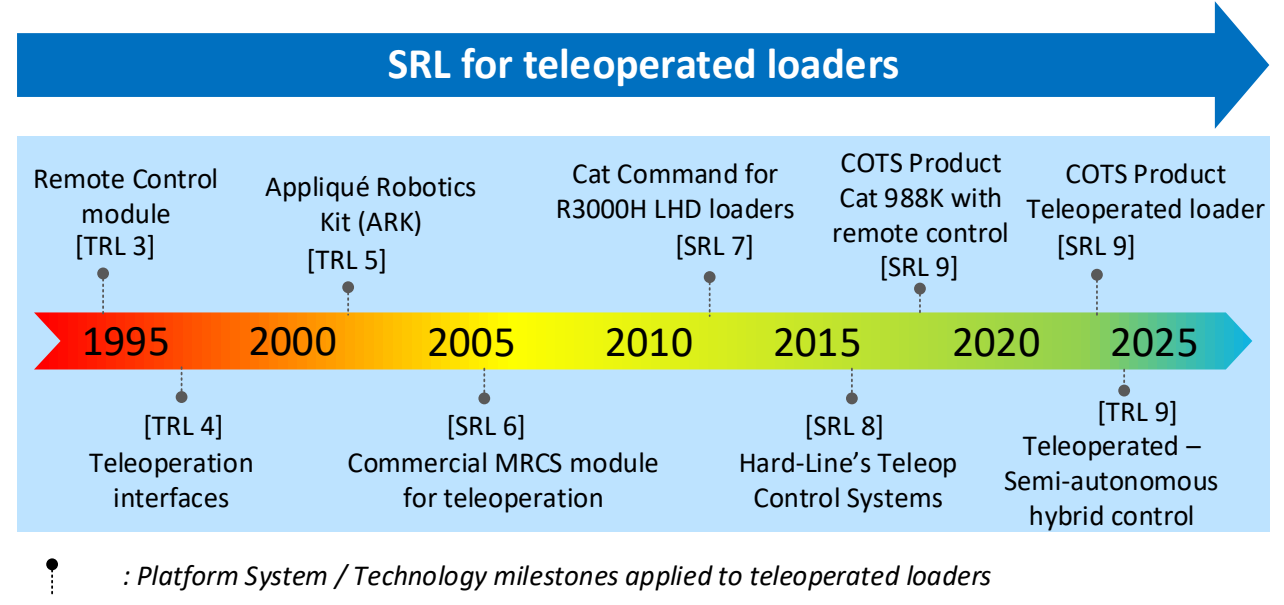

Figure 8. Projected development of remotely-controlled and teleoperated loaders.

\subsubsection{Semi-autonomous and autonomous loaders}

A number of studies have been conducted on modelling front-end loaders, considering the hydraulic, kinetic and kinematic behaviour and the four-bar linkage of the bucket actuation. Cobo et al. [60] presented a simplified dynamic model of a wheel loader, including state equations governing the dynamics across the hydraulic control valves and in the hydraulic cylinders, as well as passive soil-tool interaction loads at the bucket cutting edge. Simulation results and field test data were compared to validate the proposed model. Mathematical models of the skid-steered mobile robot were derived with the goal of developing a combination of remote-control and autonomous modes for mobile robots using the principle of telepresence, or a spatial vector-algebra tool for compact skid-steer loaders [61]. Recently, both kinematic and dynamic models of a skid-steered robot were identified via a learning process based on extended Kalman filter and an efficient neural network formulation [62]. The slip-enhanced kinematic models can then be used efficiently to provide estimates of the robot pose, while the dynamic models can be utilised to generate energy estimates and minimum turn radius constraints. In summary, various mathematical and simulation models of loaders have been developed to provide a solid foundation for control towards autonomous operation of the platform. 
Many control techniques have been developed to control loaders. Real-time control of the bucket hydraulic system for a front-end loader was developed to meet operator-perceived requirements and to create subsystems that could accept commands from an autonomous high-level planning controller. Towards autonomous operations, intelligent digging control systems are developed using a behaviourbased control structure. For this, a fuzzy logic controller was implemented in an autonomous prototype was developed on the Caterpillar 980G platform, showing the performance comparable to an expert human operator in a wide range of excavation situations [63]. Volvo Construction Equipment demonstrated its prototypes of haul truck and wheel loader platforms in September 2016 for autonomous loading of soil to the loader bucket and dumping it on the truck [64]. Later, a fully-autonomous track loader was tested and made fieldable by Built Robotics Inc. [65]. Taking advantage of advances of self-driving car technologies, the company has also developed software and sensors that can turn existing platforms to handle autonomous earthworks.

In the military domain, front end loaders are commonly used for constructing and removing road blocks and building bases and fortifications. These tasks can be much beneficial from RAS technologies in moving towards autonomy. The development progress of autonomous loaders is generally similar to that of bulldozers. As observed, the technology maturity of autonomous loaders has reached TRL 6-8 and SRL 67 for semi-autonomous loaders in a well-structured construction site. It is projected that semi-autonomous COTS product will be ready in the market within five years while fully-autonomous loading will be achievable within the next ten years due to technological advances of driverless cars. Figure 9 shows our projection for the development of autonomous loaders.

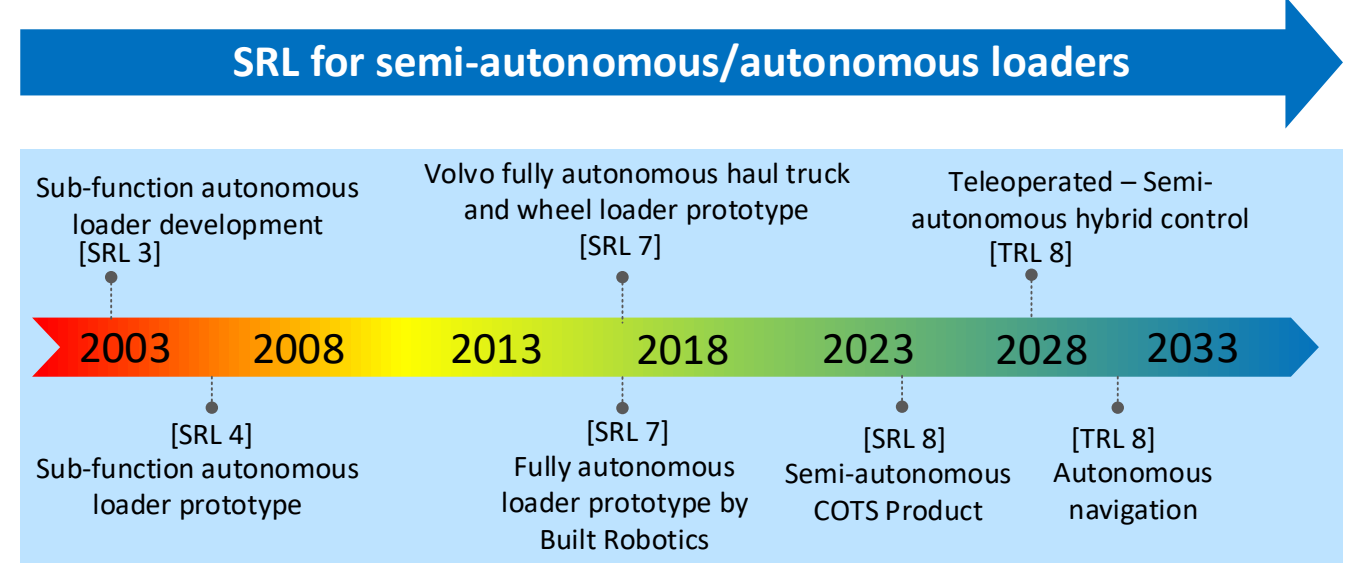

: Platform System / Technology milestones applied to semi-autonomous/autonomous loaders

Figure 9. Projected development of autonomous loaders.

\subsection{Graders and haul trucks}

Graders have been widely deployed in earthwork. Functionally-assisted control systems have been developed to manipulate grader blades to improve the productivity and efficiency of graders. In [66], a blade control system implemented on a grader for driver-assisted operations in automated road construction, where the 3-D location and position of the blade were continuously measured by a tachometer and several position sensors. Measured data were then compared with a 3-D road geometry model. Since an inverse kinematic solution exists, control data for hydraulic cylinder set-points were calculated for real-time feedback-controlled blade adjustment. The geometric accuracy of road structure layers was held within \pm 1 $\mathrm{cm}$ by the functional-assist system.

Since 2002, a Japanese company, Kajima, has implemented a three-dimensional machine control for the motor grader servicing automated road construction projects, wherein a Total Station advanced surveying instrument was used instead of GPS [67]. This local positioning system (LPS) can track the target prisms of a laser receiver installed on the grader to determine the 3-D position. Height and slope data are sent to 
the laser receiver on the grader via optical communication by using a laser beam emitted by the LPS. The system could shorten the road construction process from six to two stages and its surface accuracy could reach $\pm 2 \mathrm{~mm}$ in the trials. In a construction project in Hokkaido, Japan, the 3-D-MC system graded 6.56 $\mathrm{km}$ of expressway (135,000 $\mathrm{m}^{2}$ area), with tremendously improved accuracy: $80 \%$ of measured points were within $\pm 10 \mathrm{~mm}$ of their required 3-D positions [67].

The functional-assist mode of control has been developed for graders and is well-applied for road construction projects. However, RAS technologies have not been extensively explored for this platform at similar levels of autonomy as for excavators and bulldozers. This has been driven mainly by the market demand rather than improvements in technology, since technologies developed for other construction platforms can be applied for graders without much modification.

Driverless haulage trucks have been developed in field robotics research at the end of the $20^{\text {th }}$ century but fully remotely-controlled trucks were first used to moving iron ore in Rio Tinto's Pilbara mines in Western Australia [68]. Autonomous haulage trucks have been made commercially available for the (surface) mining industry by such vendors like Komatsu, Caterpillar, Hitachi and others. These autonomous haul trucks are, however, operated in the structured environment of a mining site, on pre-built roads within a well-understood terrain. Their job conforms to a routine: "Go to a load site, wait to be filled with ore, and then drive to a designated location." The OEM Caterpillar started selling autonomous haul trucks in 2014, guaranteeing that the haul trucks can alert the mine staff of any abnormalities on the site using their installed sensors, on-board perception systems and safety devices. Therefore, it is noted that the maturity of technologies for (fully) autonomous haul trucks in a well-structured environment and known terrain has already reached the maximum SRL.

\subsection{Cooperative multiple platforms}

The study of multi-platform systems naturally extends research on single platform systems since multiple platforms in coordination can accomplish certain tasks that a single platform barely can, or cannot at all, considering work capacity and task efficiency. Cooperative autonomous operations require the cooperating platforms to have the ability to (i) interact with other platforms performing the same or different tasks; (ii) perform a shared task in association with other platforms; (iii) autonomously divide a task between several platforms; and (iv) effectively manage and prioritise events. In earthmoving automation, methods for automatic task allocation and planning for construction equipment have been studied to provide a means of cooperation among platforms and between equipment and workers on a site. RAS-based cooperation between an excavator and a haulage truck has successfully been demonstrated using the platforms developed in the THOR project through autonomous truck loading tasks including excavation pose finding and truck location detection. There has been intensive effort of researchers devoted to cooperative control of multiple platforms in construction, see, e.g., [69]. The research involves multiagent systems [70], robotic formation control [71], system architecture and resource allocation [72]. The coordination of systems facilitates multifaceted interactions, between formations of platforms, between platforms, platformenvironment and human-platform. In military domains, typical tasks for multiple cooperating platforms include ordnance disposal, mine-clearing operations [58], de-mining and decontamination, as identified in a report from NATO [73]. Surveys of autonomous robots for military systems first appeared early in this decade, focusing on the software, control architectures and control strategies, and ground vehicles for construction earthworks [74]. Among the main tasks of unmanned vehicles in military applications a 'teaming' capability, as pointed out in [10]. Recently, the US Army has tested the autonomous vehicle technology in its fleet of logistical vehicles. The leader follower technique in robotic formation was used to form a convoy of trucks equipped with a laser-based sensor (LIDAR) used for maintaining the distance clearance. Figure 10 shows a test scenario to demonstrate the concept of V2I (vehicle to infrastructure) that allows for a formation of one manned truck leading seven driverless connected vehicles [75].

For military cooperation of unmanned vehicles, the target for mission critical operations is often in battlefields, rather than in the domain of coordination of earthmoving platforms. The technology maturity for autonomous multiplatform cooperation is at the SRL of 5-6 and will be unlikely to reach SRL 9 in the 
next fifteen years. Semi-autonomous cooperation is, however, achievable due to the rapid advances in the communications technology. Humans and robotic platforms such as unmanned aerial vehicles (UAV) will be integrated to enhance the data acquisition, processing, and decision-making capabilities. Figure 11 shows a projection of the future development of multi-platform cooperation.

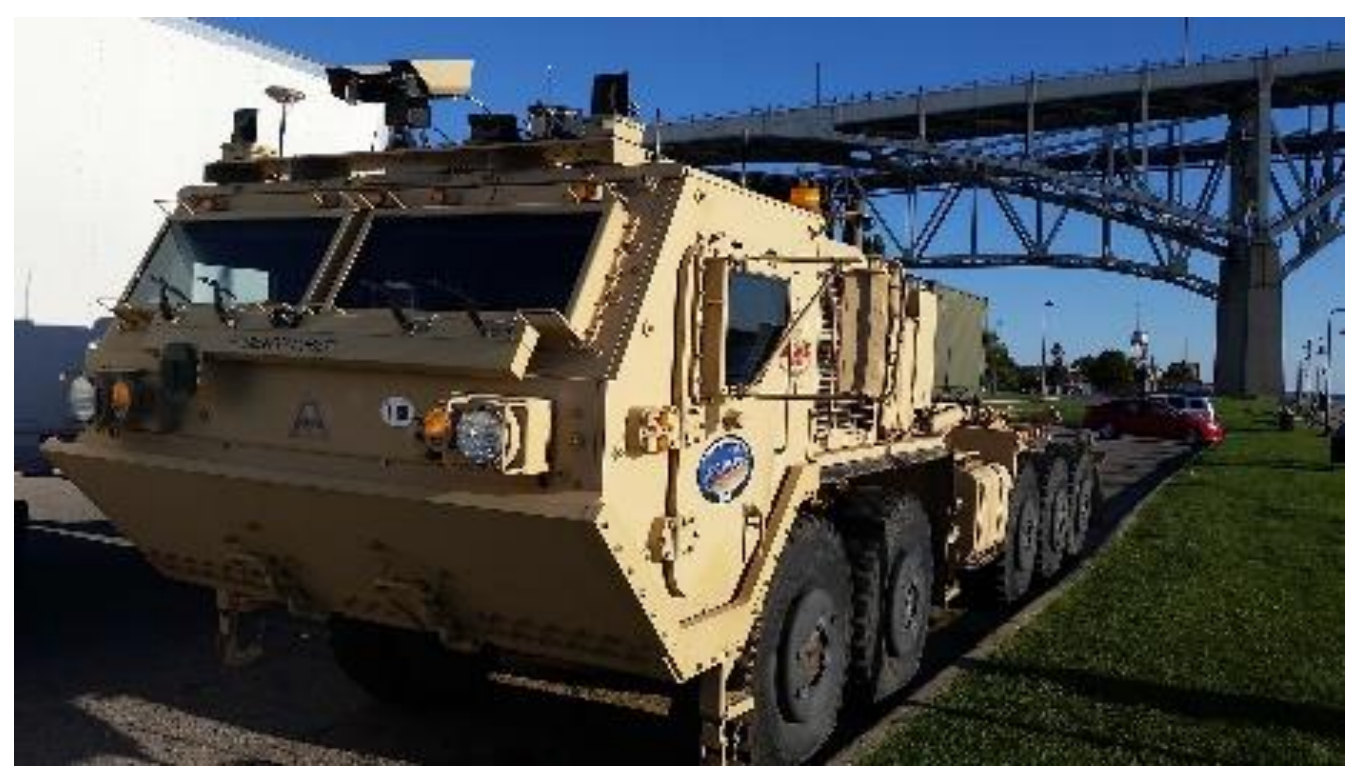

Figure 10: The US Army is testing a "leader-follower" system that will employ up to 8 convoy vehicles [75].

TRL and SRL for Multi-platform Cooperation

\begin{tabular}{|c|c|c|c|c|c|}
\hline \multirow[t]{2}{*}{ 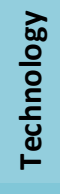 } & $\begin{array}{l}\text { Multi } \\
\text { agents }\end{array}$ & $\begin{array}{c}\text { Formation } \\
\text { control }\end{array}$ & $\begin{array}{l}\text { Internet of } \\
\text { Things }\end{array}$ & \multicolumn{2}{|c|}{$\begin{array}{l}\text { Global mesh } \\
\text { networking }\end{array}$} \\
\hline & 2018 & & 202 & 2028 & 2033 \\
\hline$\frac{\varepsilon}{\stackrel{\varepsilon}{n}}$ & $\begin{array}{l}\text { Human- } \\
\text { machine } \\
\text { cooperation }\end{array}$ & $\begin{array}{r}\text { Mac } \\
\text { coo } \\
\text { huma }\end{array}$ & $\begin{array}{l}\text { ine-machine } \\
\text { seration via } \\
\text { intervention }\end{array}$ & $\begin{array}{l}\text { Partial cooperation with non- } \\
\text { construction platform (UAV, } \\
\text { UGV), ground sensors, beacons }\end{array}$ & $\begin{array}{l}\text { semi-autonomous } \\
\text { cooperation }\end{array}$ \\
\hline
\end{tabular}

- : TRL/SRL 9 milestones

Figure 11. Projection of the future development of multi-platform cooperation.

\section{Selected earthmoving tasks using RAS technologies}

In this section, the application of RAS technologies to these tasks for defence purposes is reviewed with an emphasis on the task efficiency and work capacity aspects. The trends of RAS technologies applied to the domain are projected for the next fifteen years in terms of platform-centric modes of control.

\subsection{RAS applications to military earthmoving tasks}

In army applications, the construction tasks involving earthworks are described briefly in the following together with applications of the RAS technologies to the corresponding platforms. 


\subsubsection{Land clearance}

Land clearance is the process of removal and disposal of all vegetation, rubbish, and surface boulders embedded in the ground. In the current project, the focus is on clearing rubbish or existing structures, removing vegetation, and stripping grass and topsoil. The task is typically carried out via two stages. First, a survey on the site to be cleared is conducted following by the setting out of equipment. Excavators, frontend loaders, and bulldozers are then used to remove the rubbish, structures, vegetation and/or topsoil. Land clearance is typically carried out in two stages: site survey, followed by material removal, as discussed previously. While the former stage may in part be manually accomplished, the latter can be automated using RAS for teleoperation of such platforms as excavators, bulldozers and loaders.

As a demonstration of RAS applications to land clearance, three Caterpillar 521B tracked 'fellerbunchers' were remotely-controlled for clearance of about 980 acres by removing trees and other vegetation, one fitted with a disc saw head for felling large timber while the others equipped with mulching heads for clearing trees and brush of smaller diameter [76]. In the military domain, teleoperated land clearance experiments have been conducted by the CERK Warfighter Experiment Team at Fort Leonard Wood MO, USA [30]. The Appliqué Robotics Kit (ARK) and Modular Robotic Control System (MRCS) were respectively installed on the HMEE III Front End Loader and the Caterpillar 924G bucket loader to provide them with teleoperation capability. Experiments were designed to assess whether an unmanned backhoe and/or bucket loader could successfully accomplish specific route-clearance missions. There were seven vignettes designed to address the experiment issues; four for the robotic backhoe, and three for the robotic bucket loader. Though not all the test runs and vignettes were successful, it was concluded that (i) both unmanned backhoe and unmanned bucket loader were effective in specific route-clearance tasks, and (ii) unmanned backhoe and bucket loader were able to operate in all environmental conditions, reduce the impact on manpower and training requirements, and avoid human factors. An important advantage regarding the working environment concern is the ability to efficiently operate under different lighting conditions.

\subsubsection{Hesco basket filling and soil compaction}

The Hesco bastion is a modern gabion primarily used for flood control and military fortification. In the ADF, Hesco is commonly-used in a FOB wall as a temporary-to-semi-permanent levee or blast barrier against explosions or small arms fire. One of the best features of the Hesco bastion is the ease with which it is set up: unload a Hesco basket from a truck, unfold and erect it, insert the geofabric liner, and use a front-end loader, back hoe or skid-steer loader (for smaller units) to fill the basket with dirt, sand or gravel. Figure 12 shows a HESCO bastion installed by US Marine Corps with the help of an excavator [77], for a FOB in Afghanistan's Delaram District. Linked baskets can be loaded in a trailer and dropped out in a line at high speed, resulting in an (unfilled) chain of several hundred metres of Hesco baskets in a few minutes. A high-speed system can be made available for automatic filling and levee or gabion construction.

As an important operation for land forces, filling Hesco baskets can rely on RAS technologies. First, autonomous dump trucks are deployed to deliver Hesco baskets and sand to the site. The baskets are then unfolded and erected either manually or automatically depending on their types. For example, the Hesco RAID 7 type can be loaded into a trailer and dropped out in a line at high speed, resulting in placing several hundred metres of a chain of Hesco baskets in a few minutes. Teleoperated and autonomous loaders or excavators are able to deposit sand into each basket. For teleoperation, external visual feedback and distance sensors may be needed to locate the basket position for the filling task. Multiple front-end loaders, backhoe loaders and/or excavators can be coordinated to operate in parallel at this stage. Machine-to-machine communication channels and drones can also be used to enhance the cooperation of the platforms and to provide site information to the control centre. For smaller Hesco baskets, multiple autonomous skid-steered loaders such as those developed by Built Robotics Inc. [65] could be used to achieve higher efficiency and 
accomplish higher work capacity. The automated filling process, however, becomes more complicated when a second layer of Hesco baskets have to be installed, with additional empty Hesco units stacked on top of the filled Hesco units. In this scenario, labour may be required to stack the Hesco units. Additional sensory systems would also be needed to locate the new baskets which then sit at a relatively high position.

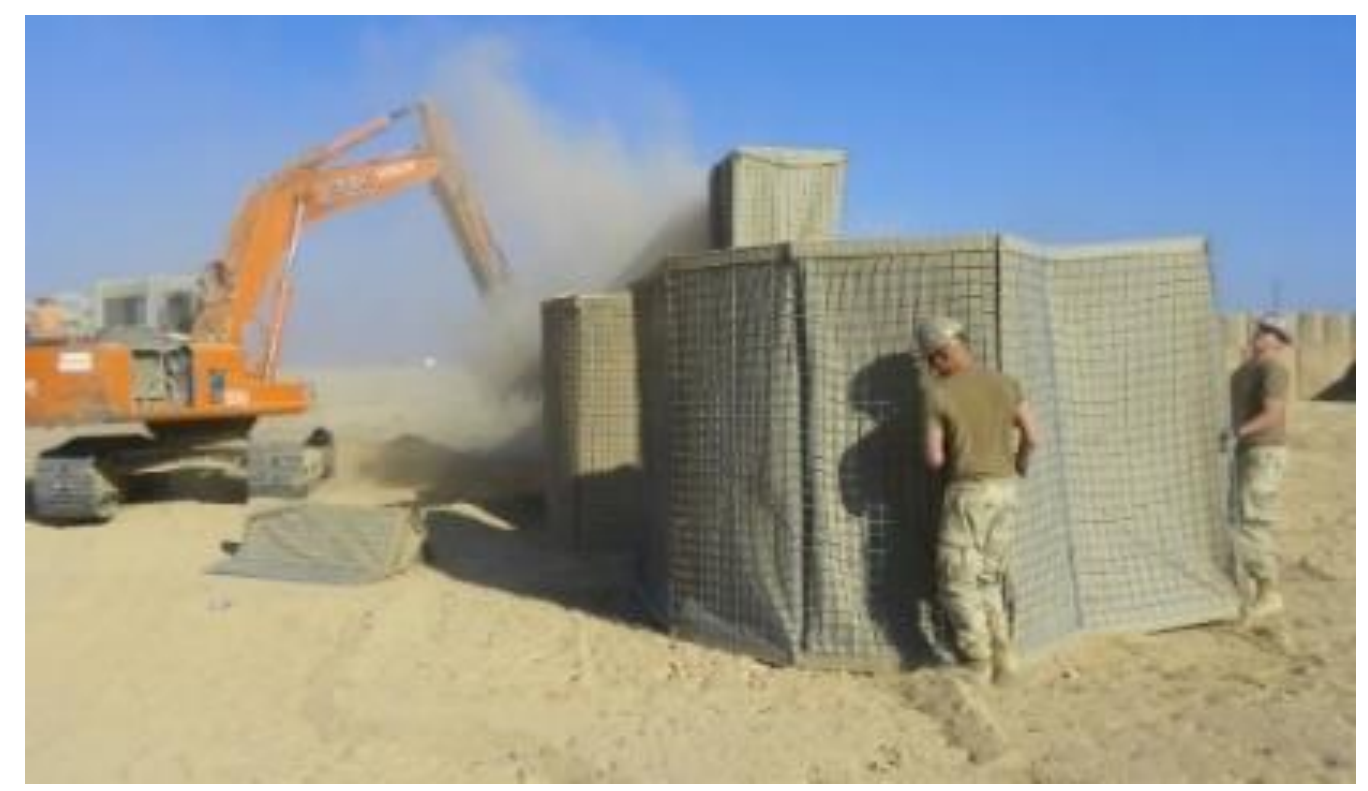

Figure 12: Building Delaram FOB [77]

Soil compaction is a vital part of the construction process to support structural entities such as building footings and foundations, roadways, walkways, and earth retaining structures. Compaction is also important to ensure the effectiveness of filled Hesco baskets. For a given soil type certain properties may deem it more or less able to achieve adequate compaction for a particular circumstance. In general, the preselected soil should have adequate strength, contain a suitable distribution of particle sizes, be relatively incompressible so that future settlement is not significant, be stable against volume change as water content or other factors vary, be durable and safe against deterioration, and possess proper permeability. Typical techniques for compacting soil include static force, impact, vibrating, gyrating, rolling, and kneading to be chosen in accordance with the soil composition, properties and conditions. For RAS-based soil compaction, it is possible to use a compaction attachment fitted to an excavator arm. Compaction attachments may take the form of tamping plates or vibratory plates and use a closed-loop control system to compact the soil. For this, hydraulic-powered vibration is used for removing air and shifting soil to increase its density, or applying a force to physically push soil into place. Soil compactness is measured by a soil penetrometer while 2-D or 3-D soil compaction maps are generated for different depth soil layers [78]. The penetrometer, consisting of a force sensor, a soil depth sensor, and a data acquisition and processing module can be attached to the compactor in the teleoperated or autonomous mode of control.

\subsubsection{Dirt bunding}

In civil construction a bund is a mound or wall around a tank or liquid storage container, formed to contain any unintended escape of liquid from the area until remedial action can be taken. There are several different types of bunds, such as ramp, hump and square bunds. In a military context, a bund may have the same purpose, or may serve to effectively deepen trenches or protect emplaced field artillery. Dirt bunds are created by using either front-end loaders or bulldozers. RAS technologies can be applied to improve the efficiency of mounding dirt bunds. Specifically, various teleoperated and functionally-assisted bulldozers are currently available in the market for dirt bunding. An operator located in a trailer about $100 \mathrm{~m}$ away 
can control a bulldozer pushing up dirt using the views captured from cameras installed on board the bulldozer. In addition, the front-end loaders with functional assist capabilities can also be used to speed up the dirt bunding process.

\subsubsection{Borrow pit operation}

Borrow pits are small sites in close proximity to civil construction works where soil, gravel, or rock is removed to be used on-site for foundations, road-base, embankments, or backfilling. The process of operating a borrow pit is typically comprised of three subtasks: excavate suitable materials, crush materials to the required size if necessary, and transport the crushed materials to the construction site. An intermediate size-grading task may be required for road-base. These tasks typically require excavators, front-end loaders, and dump trucks as a minimum, together with crushing, grading and blending machinery for road-base production. Operating a borrow pit, or gravel pit, often requires the deployment of such platforms as excavators, front-wheel loaders and dump trucks to undertake three subtasks: capture material, crush material, and cart crushed rock. The quantity of material available in a gravel pit is determined from a location survey, and the location of suitable material is determined by a geotechnical analysis. Excavators or front-end loaders are employed, using either teleoperated or semi-autonomous technologies, to dig material and crush it to a size distribution suitable for road-base. Cooperation between a haul truck and excavator needs to occur to load the crushed rock [46]. The final stage is to deliver loaded materials to designated locations, which can be carried out with the use of a fully autonomous truck. However, the task efficiency will need to be verified with experiments.

\subsubsection{Unsealed road construction}

The term "unsealed roads" refers to roads that have been constructed with a high content of size-graded rock or recycled rubble material, well compacted to provide an all-weather surface. The construction task includes several subtasks involving bulldozers, graders, vibrating rollers and trucks. Bulldozers are used to cut away topsoil and undergrowth down to subgrade along the designated route. Rollers are employed to compact subgrade and materials. Graders trim and spread materials whereas dump trucks deliver materials. Unsealed road construction is a complicated construction task involving various stages and different platforms such as the bulldozer, grader and dump truck. As with operating a borrow pit, automating the whole process may be infeasible, but subtasks can be performed with RAS applications. For instance, a robotic bulldozer can be controlled to automatically remove the undergrowth and topsoil down to sub-grade along a designated route, and a grader can be teleoperated to trim the subgrade.

The challenge here is the coordination among stages. This requires the communication between machines together with external monitoring systems such as drones to provide site-wide information. It implies the transformation of the holistic construction area into digital information so that the data can be transparently exchanged between vehicles, machines and devices, and every part of the construction site can be monitored by external sensors. In this regard, the construction automation process can be well advanced using the emerging technologies of network-centric warfare. It represents the synergistic integration of strategies, campaigns, methods and procedures via self-synchronization and network-centric operations, resulting in a significant reduction of time, capital and human resource [79].

\subsubsection{Anti-tank ditching}

On an open site, anti-tank ditches are large trenches constructed to strengthen the required defensive positions. They are usually triangular, rectangular, or trapezoidal in cross section and have a low parapet formed on the defender's side. The construction can be carried out by excavators and front-end loaders, or pairs of bulldozers. An excavator and a front-end loader can also be paired for this task. If two bulldozers are used, one will push earth along the line of the trench while the other will work perpendicular to the trench line to form the batter. Figure 13 shows the Terrier combat teleoperated drive-by-wire vehicle when under development by BAE Systems for the British Army [80]. The armoured tracked vehicle is equipped with a hydraulically-actuated front bucket and an excavating arm such that it can be remotely controlled 
not only to clear routes or create cover, but also to dig trenches for troops on the ground, or to hollow out anti-tank ditches. It is believed that the described technology can assist the operators constructing turretdown and hull-down defilade fighting positions in harsh conditions as well as digging anti-tank ditches with both deliberate or hasty cratering.

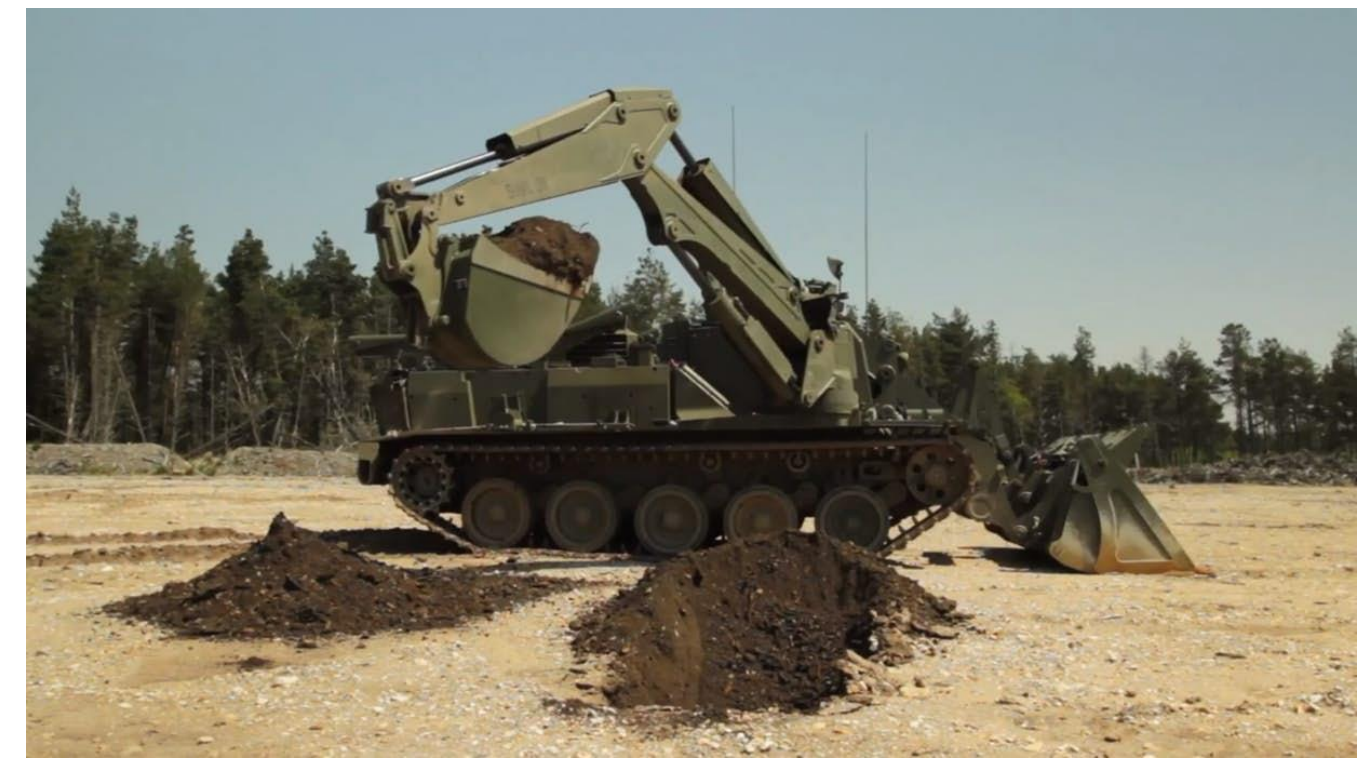

Figure 13. Early BAE Systems Terrier vehicle for teleoperated trench digging [80].

The construction of anti-tank ditches is similar to digging a large open drain. In [44] an excavation system with function-assist was developed by Komatsu for excavating drainage ditches. This system was composed of a rotating laser transmitter which projected a laser beam to indicate a desired surface, and an excavator equipped with a laser beam receiver, angle sensors, an operation display, a controller and proportional solenoid valves. The position of the laser beam was detected by the laser receiver from which the height information of the excavator body was calculated and sent to the automatic surface finishing system. Given the height and angle information available to the automatic surface-finishing system, the distance from the desired surface to the bucket-tip position was calculated and used to control the hydraulic cylinder. Experiments were conducted by excavating a ditch of $8 \mathrm{~km}$ in length. The results presented therein show that the task efficiency using function-assist increased 1.6 times in terms of work rate, with a substantial reduction of operator number while the accuracy was substantially improved by a factor of four compared to manual control.

Apart from the abovementioned system, the various teleoperated and semi-autonomous construction platforms previously discussed can be used to partially- or fully-automate a digging task. Cutting ditches is, however, more complicated than trenching, as the cooperation of two construction machines is required. Operator training will therefore need to include techniques for controlling two teleoperated machines working in a pair.

\subsection{Work capacity and task efficiency}

Various studies have been conducted to evaluate the work capacity and task efficiency when applying RAS. In accordance with [44], studies by Komatsu also showed that by using the functional-assisted excavator PC210LCi-10, the construction time was reduced down to $63 \%$ compared with conventional staking/construction/inspection processes, and with much higher accuracy in finished surface levels [17]. It also eliminated constant repetition of inaccurate work and substantially reduced project costs. For example, functional assist modules such as Slope Assist by the OEM Caterpillar for grade control have 
proved to produce better quality grading surfaces in a timely fashion without any external laser or GPS reference and regardless of the operator experience.

\subsubsection{Task efficiency evaluation}

In teleoperation, experiments to assess whether an unmanned backhoe and/or bucket loader could successfully accomplish specific missions. Experimental results for the backhoe loader showed a high success rate with $100 \%$ achieved in the 'filling' task while for the bucket loader, the mission success rate averaged $73 \%$ with the highest successful rate $100 \%$ for moving Jersey barriers and lowest for removing rubble [30]. In another project, Caterpillar introduced a system called Cat Command that improved the consistency and efficiency of bulldozing operations at the Arch Coal Black Thunder mine in Wyoming USA. The teleoperated system allows one operator to control up to three machines simultaneously from a remote location. In addition to improved work efficiency, operators also experienced less physical fatigue thanks to the improved working conditions. By controlling the bulldozers from a distance, operators could be located in an office setting, protected from various environmental hazards. The teleoperated platforms would potentially enable them to be run for more hours compared to a human operator. For improved safety, the OEM has developed functional-assist teleoperated loaders, which are currently operating at various mines around the world. As with bulldozers, the operator can be remotely located at the surface of a mine and uses tele-remote control to manoeuvre the platform. Thus, RAS technologies allow for faster travel speeds and near-zero damage to the machine.

Remotely controlling earthmoving platforms not only keeps operators safe, but also enables loads to be delivered in an efficient manner. For example, autonomous trucks can move along a predetermined route at a set speed, resulting in savings in maintenance, tire life and fuel as well as eliminating potential for fluctuations that might otherwise occur with a human operator and negatively affect efficiency or productivity. Significant productivity benefits and savings can be attributed to automation: autonomous trucks in operation could result in a $13 \%$ reduction in load and haul costs due to the autonomous trucks' efficiencies [81]. To demonstrate the task efficiency of autonomous wheel loaders, as per testing at a customer's asphalt plant of Volvo Construction Equipment, an autonomous wheel loader could reach the equivalence of $70 \%$ of a skilled operator's productivity levels for one hour when loading and unloading, but at a much higher level of safety [64]. An autonomous machine can also be controlled more efficiently and precisely than even the most skilful human operating the platform, allowing for increased efficiency gains such as fuel economy, machine performance, and vehicle durability, especially during repetitive tasks. Accordingly, it is expected to have a single operator control three or four machines at a time, further increasing productivity while at the same time reducing labour costs.

\subsubsection{Work capacity in night conditions}

The semi-autonomous platforms with RAS technologies are expected to significantly improve the work capacity as well as task efficiency, over those with manual or remote-control modes in low light environments. While visual-wavelength cameras for perception are strongly affected by the lighting condition, fortunately most sensors used in semi-autonomous platforms such as LIDAR, radar, ultrasonic sensors, force sensors, GPS receivers and IMUs are not. When cameras are coupled with night vision systems such as infrared and low-light night vision devices, the sensing capability can meet the requirement for environment awareness. The night vision technology for military deployment has matured with COTS and MOTS platforms available from multiple suppliers.

Regardless of sensory systems, functional-assist and semi-autonomous platforms will help improve the night operation capacity because most functions that require skilled control by the operator can be automated. The advantage of using RAS technologies for earthmoving platforms in night operations has been demonstrated in mining. For example, a fleet of autonomous haul trucks can be monitored by a control centre located thousands of kilometres away. Operating 24 hours a day, seven days a week, these 
autonomous trucks can bring a significantly higher safety record and increased productivity to ore transportation.

\subsection{RAS projection for selected earthmoving tasks}

Automation has been used in various forms of civil and military construction. The level of automation that a ground-based platform exhibits during earthmoving and material handling can be judged via the five proposed modes of control (MoC's) presented in Section 2.1, ranging from functional-assist (MoC 1) to multi-platform cooperation (MoC 5). There will be an increasing need for RAS applications in military operations, particularly related to construction, because of distinct advantages in (i) removing personnel from $3 \mathrm{D} / 3 \mathrm{H}$ missions (those that are dull, dirty and dangerous/harsh, hostile and hazardous); (ii) the higher task efficiencies available by using RAS; and (iii) the improved work performance considering human endurance and response times. These advantages have been experimentally demonstrated in the platforms considered in this paper, which can be individually or cooperatively deployed to accomplish an earthwork task. Land clearance, for example, requires excavators, loaders and bulldozers, while construction of an unsealed road would need bulldozers, graders, and dump trucks, potentially with the addition to more specialised plant such as rock crushers, water trucks, sheep's foot rollers and vibrating rollers. Loaders and excavators are to be deployed for erecting Hesco bastion, potentially with specialised machinery for holding baskets for filling and for stacking filled baskets. Bulldozers or loaders are needed for forming dirt bunds; excavators, bulldozers and loaders for antitank ditching; and excavators, loaders, and dump trucks for operating borrow pits. For tasks such as forming dirt bunds or anti-tank ditching, or even the filling of Hesco baskets, the construction process is rather simple, with one or two stages. Automation can therefore be quickly developed and applied to obtain a higher $\mathrm{MoC}$, as compared to more complicated tasks such as road construction. It is predicted that fully autonomous systems will be available for dirt bunding and antitank ditching tasks by 2033 due to rapid advancements in the driverless car industry.

Although RAS applied to earthmoving tasks may appear to be technologically common across platforms, the level of automation exhibited by each platform can be different, depending on various factors. The key drivers affecting the widespread use of a MoC on a platform are the demand from end-users, the market return for developers and manufacturers, support from government and $\mathrm{R} \& \mathrm{D}$ activities in industry and academia. Based on the analysis of RAS technology developments for construction platforms presented in previous sections, the platform-centric estimation for future applications of RAS for earthmoving equipment is suggested in Table I.

Table I. Projected achievement dates of modes of control for ground-based platforms in typical construction tasks.

\begin{tabular}{lccc}
\hline Construction platform & $\mathbf{2 0 1 8}-\mathbf{2 3}$ & $\mathbf{2 0 2 3}-\mathbf{2 8}$ & $\mathbf{2 0 2 8}-$ \\
\hline Excavator & MoC 1 & MoC 2/3 & MoC 2+/3+ \\
Loader & MoC 2 & MoC 3 & MoC 3+ \\
Dozer & MoC 2 & MoC 3 & MoC 3+ \\
Dump truck & MoC 5 & MoC 5 & MoC 5 \\
Grader & MoC 1 & MoC 1 & MoC 2+ \\
\hline
\end{tabular}

As the dump (or haul) truck is required in almost all construction (and mining) sites, the high demand and market return, along with advances in RAS technologies, have led to the current commercial availability of fully autonomous haul trucks at MoC 4, with COTS systems in operation at some mining sites. Over the next five, ten, and fifteen years, dump trucks will continue to operate in the fully autonomous mode due to their maturity in technologies and will reach MoC 5 when applied to cooperative tasks with other RAS-enabled platforms.

Graders, on the other hand, are commonly used for road construction. As much road construction is under government management the demand for automation is not high. It is expected that a grader of the future will use RAS technologies in functionally-assisted or teleoperated modes of control in cooperation 
with other platforms. It is believed that the semi-autonomous control mode (MoC 3) for excavators may become available earlier than teleoperation due to a high demand of the market rather than technological complexity. Compared to excavators, loaders and bulldozers have less degrees of freedom to control and can therefore reach a higher MoC in the next five years.

With intense R\&D activities devoted to the areas of multi-agent systems, cyberphysical systems, interconnected systems, coordination and formation control [82], artificial intelligence and robotics [83], the ground-based platforms mentioned will have capabilities to cooperate, via either direct machine-tomachine interaction or human-machine interaction [84], overcoming technology gaps [85], to fully automate military construction tasks. Together with RAS advancements in sensing and navigation and the maturity of monitoring technologies with air-based platforms such as unmanned aerial vehicles, it is predicted that future military construction will mainly rely on hybrid operations. These can combine autonomous, semi-autonomous and teleoperated modes of control in a working environment that can operate efficiently on a 24/7 basis and require minimal human presence. Complex issues resolved with data and digital intelligence will result in new concepts of operations (CONOPS) for military earthmoving tasks to be executed using RAS-based platforms and the available resources.

\section{Conclusion}

The introduction of robotic autonomous systems to the construction industry has been underway for nearly half a century with cognate research commencing at least four decades ago. Naturally there is also an increasing interest in utilizing RAS technologies in the construction activities of many military forces. In particular, ground forces are frequently called upon to complete earthwork tasks as part of military operations, tasks which could be partially or fully aided by employing RAS technologies. There have been rapid developments in military construction automation using high-mobility ground-based platforms, human-machine and machine-machine interfaces, teleoperation and control systems, data transmission systems, machine perception and manipulation capabilities, as well as advances in networked robotics and cyberphysical systems. As such, it is timely to undertake a general review of these developments with an outlook into the next stage. This paper has presented a comprehensive overview and analysis of the technical feasibility, maturity, key technical challenges and future directions for the application of RAS to earthmoving tasks, with an emphasis on selected army applications. Typical automated platforms such as excavators, bulldozers and front-end loaders are reviewed with regard to modeling, low and high levels of control, their system architecture, sensing and navigation, tool-soil interactions, simulation and experiments from laboratory set-ups to full-scale field tests, in remotely controlled, teleoperated, semi-autonomous and autonomous operations, which are distinguished in our analysis as modes of control. The developments of RAS for these platforms have been perused from over the time. Here an emphasis of our overview of these is placed on their technology maturity and systems readiness. These developments range from basic research through to operationally employed systems. From this basis abreast recent advances in construction robotics and automation, a predictive projection to the future is presented for earthwork platforms and selected earthmoving tasks in the military domain.

To judge the level of autonomy with regards to the platform-centric control of earthmoving platforms, our evaluation is based on the proposed modes of control, from functional assist, teleoperation, semi-autonomy to full autonomy and cooperation. While RAS technologies have significantly enhanced the work capacity and task efficiency with higher levels of technical maturity for a type of ground-based machines, the trend of platform teaming and RAS development for cooperative operations of unmanned platforms will be subject to further research in military earthmoving. At the highest mode of control, these will include interacting with humans and inhabited machines, or interacting among themselves to execute the same or different tasks, decomposing a task and allocating subtasks among several platforms, performing a shared task in association with other platforms, managing and prioritising events, to cooperatively handle more sophisticated tasks with higher efficiency. 


\section{Acknowledgements}

Support received from the Land Division, Defence Science and Technology Group of the Australian Government and the UTS Distinguished Visiting Scholar scheme is gratefully acknowledged. The authors would like to thank Prof. Miroslaw Skibniewski, Mr Stephen Baker, A/Prof David Rye for fruitful discussion and improvements, and Dr Danny Phung for assistance during the preparation of this work.

\section{References}

[1] Skibniewski, M. "Current status of Construction Automation and Robotics in the United States of America," Proc. $9^{\text {th }}$ Int. Symp. Automation and Robotics in Construction, Tokyo Japan. 1992. DOI 10.22260/ISARC1992/0003

[2] Dadhich, S., Bodin, U. and Andersson U. "Key challenges in automation of earthmoving machines". Automation in Construction, 68: 212-222, 2016. DOI 10.1016/j.autcon.2016.05.009

[3] Azar, E.R. and Kamat, V.R. "Earthmoving equipment automation: a review of technical advances and future outlook". J. Information Technologies in Construction, 22(13): 247-265, 2017. http://www.itcon.org/2017/13.

[4] Balaguer, C. and Abderrahim, M. "Trends in Robotics and Automation in Construction," in Robotics and Automation in Construction (Eds. C. Balaguer and M. Abderrahim) InTech 2008. DOI 10.5772/5865

[5] Sapaty, P. "Military robotics: latest trends and spatial grasp solutions." International Journal of Advanced Research in Artificial Intelligence, 4(4): 9-18, 2015. DOI 10.14569/IJARAI.2015.040402

[6] Czarnowski, J., Dąbrowski, A., Maciaś, M., Główka, J. and Wrona, J. "Technology gaps in Human-Machine Interfaces for autonomous construction robots", Automation in Construction, 94: 179-190, 2018. DOI 10.1016/j.autcon.2018.06.014

[7] Ha, Q.P., Yen, L. and Balaguer, C. "Earthmoving construction automation with military applications: past, present and future," in Proceedings of the 35th International Symposium on Automation and Robotics in Construction (ISARC'18), Berlin, Germany, pp. 1164-1174, 2018. DOI 10.22260/ISARC2018/0164.

[8] Defence Science and Technology Organisation, "Technical risk assessment handbook", Australia government, 2010. Online: www.dst.defence.gov.au/sites/default/files/basic_pages/documents/Technical-RiskAssessment-Handbook_2.pdf [accessed 15 Aug 2018].

[9] Insaurralde, C.C. and Lane, D.L. "Metric assessment of autonomous capabilities in unmanned maritime vehicles," Engineering Applications of Artificial Intelligence, vol. 30, pp. 41-48, 2014. DOI 10.1016/j.engappai.2013.09.003

[10] Finn, A. and Scheding, S. Developments and Challenges for Autonomous Unmanned Vehicles, Springer, 2010 ISBN 978-3-642-10704-7. DOI 10.1007/978-3-642-10704-7.

[11] Durst, P.J. and Gray, W, "Levels of Autonomy and Autonomous System Performance Assessment for Intelligent Unmanned Systems," The US Army Engineer Research and Development Center, Report ERDC/GSL SR-14-1, 2014. http://www.dtic.mil/dtic/tr/fulltext/u2/a601656.pdf

[12] SAE International, Automated Driving, 2017. Online: https://web.archive.org/web/20170903105244/ https://www.sae.org/misc/pdfs/automated_driving.pdf, [Accessed $23 \mathrm{Feb} 2018]$.

[13] Cadena, C., Carlone, L., Carrillo, H., Latif, Y., Scaramuzza, D., Neira, J., Reid, I. and Leonard, J. (2016). "Past, Present, and Future of Simultaneous Localization and Mapping: Toward the Robust-Perception Age," IEEE Transactions on Robotics, 32 (6): 1309-1332, 2016. DOI 10.1109/tro.2016.2624754

[14] Ha, Q.P. and Rye, D.C. "A control architecture for robotic excavation," Computer-Aided Civil Engineering and Infrastructure, 19: 28-41, 2004. DOI 10.1111/j.1467-8667.2004.00335.x

[15] Akanmu, A., Anumba, C. and Messner, J. "Scenarios for cyberphysical systems integration in construction," Journal of Information Technology in Construction, 18: 241-260, 2013. http://www.itcon.org/2013/12 [accessed 15 JAN 2018] ISSN 1874-4753

[16] Fukukawa, M. and Yamaguchi, T. "Application of 3-D-MC for Road Construction Machine," in Proceedings of the 21 st International Symposium on Automation and Robotics in Construction (ISARC'04), Jeju, Korea, 2004. DOI 10.22260/ISARC2004/0014

[17] Komatsu Ltd. https://www.komatsu.com.au/company/news-media/news/komatsu-launches-world-s-firstintelligent-machine [Accessed 15 Mar 2019].

[18] Burks, B. L., Killough, S. M., and Thompson, D. H. "Remote excavation using the telerobotic small emplacement excavator," Trans. American Nuclear Society; ISSN 0003-018X; 66: 559-560; Joint American Nuclear Society (ANS)/European Nuclear Society (ENS) international meeting, Chicago, IL, 15-20 Nov 1992. https://www.osti.gov/biblio/6678879-remote-excavation-using-telerobotic-small-emplacement-excavator [Accessed 15 March 2019].

[19] Hasunuma, H., Nakashima, K., Kobayashi, M., Mifune, F., and Yanagihara, Y. “A tele-operated humanoid 
robot drives a backhoe," in Proceedings of IEEE International Conference on Robotics and Automation (ICRA'03), Taipei, Taiwan, pp. 820-826, 2003. DOI 10.1109/ROBOT.2003.1242051

[20] Kim, D., Kim, J., Lee, K., Park, C., Song, J. and Kang, D. "Excavator teleoperation system using a human arm," Automation in Construction, 18(2): 173-182, 2008. DOI 10.1016/j.autcon.2008.07.002

[21] Sasaki, T. and Kawashima, K. "Remote control of a backhoe at construction site with a pneumatic robot system," Automation in Construction, 17(8): 907-914, 2008. DOI 10.1016/j.autcon.2008.02.004

[22] Kamezaki, M., Iwata, H., and Sugano, S. "Development of an operation skill-training simulator for doublefront construction machinery: Training effect for a house demolition work," Journal of Robotics and Mechatronics, 20(4): 602-609, 2008. DOI 10.20965/jrm.2008.p0602

[23] Nagatani, K. "Recent trends and issues of volcanic disaster response with mobile robots," Journal of Robotics and Mechatronics, 26(4): 436-441, 2014. DOI 10.20965/jrm.2014.p0436

[24] Egawa, E., Kawamura, K., Ikuta, M., and Euchi, T. "Use of construction machinery in earthquake recovery work," Hitachi Review, 52(2): 136-141, 2013.

[25] Koivo, A., Ramos, M., and Thoma, M. "Dynamic model for excavators (and backhoes)," IFAC Proceedings Volumes, 27(14): 763-768, 1994. DOI 10.1016/S1474-6670(17)47394-0

[26] Ha, Q.P., Nguyen, Q., Rye, D. and Durrant-Whyte, H., "Impedance control of a hydraulically actuated robotic excavator," Automation in Construction, 9(5-6): 421-435, 2000. DOI 10.1016/S0926-5805(00)00056-X

[27] Xia, K. "A framework for earthmoving blade/soil model development," Journal of Terramechanics, vol. 45, pp. 147-165, 2008. DOI 10.1016/j.jterra.2008.11.002

[28] Yaojuan, Z., Kai, C., Peng, Z., and Zhilin, W. "Research on the simulation of the driving system of crawler bulldozer," in Proceedings of International Conference on Transportation, Mechanical, and Electrical Engineering (TMEE'11), Changchun, China, 2011. DOI 10.1109/TMEE.2011.6199299

[29] Volvo Construction Equipment https://www.volvoce.com/global/en/this-is-volvo-ce/what-we-believein/innovation/gaiax-compact-excavator-concept/ [Accessed 15 Mar 2019].

[30] Theisen, B. and Richardson. P. "Construction engineering robot kit: warfighter experiment," Intelligent Robots and Computer Vision XXVI: Algorithms and Techniques. Vol. 7252. 2009. DOI 10.1117/12.805995

[31] Leonardo DRS http://www.leonardodrs.com/news-and-events/press-releases/drs-technologies-andautonomous-solutions-form-strategic-partnership-to-develop-technology-to-protect-troops-from-roadsideexplosives/ [accessed 25 April 2018]

[32] Whittaker, W. and B. Motazed, B. "Evolution of a robotic excavator," in Proceedings of the 3rd International Symposium on Automation and Robotics in Construction (ISARC'85), Marseille, France, 1985. DOI 10.1007/978-1-4684-7404-6_23

[33] Budny, E. and Gutkowski, W. "Kinematic induced excavation by backhoe excavator," in Proceedings of the 13th International Symposium on Automation and Robotics in Construction (ISARC'96), Warsaw, Poland, pp. 673-680, 1996. DOI 10.22260/ISARC1996/0079

[34] Zhou, J., Shen, X., and Tu, Q. "Modeling of operation function of the unmanned excavator in the deterministic surfacing process," Applied Mechanics and Material, 741: 526-530, $2015 . \quad$ DOI 10.4028/www.scientific.net/AMM.741.526

[35] Maeda, G.J. Learning and Reacting with Inaccurate Prediction: Applications to Autonomous Excavation, PhD Thesis, University of Sydney, 2013.

[36] Song, B. and Koivo, A. "Neural adaptive control of excavators," in Proceedings of IEEE/RSJ International Conference on Intelligent Robots and Systems - Human Robot Interaction and Cooperative Robots, Pittsburgh, PA, pp. 162-167, 1995. DOI 10.1109/IROS.1995.525791

[37] Shi, X., Wang, F.-Y., and Lever, P. "Experimental results of robotic excavation using fuzzy behavior control," Control Engineering Practice, 4(2): 145-152, 1996. DOI 10.1016/0967-0661(95)00220-0

[38] Vähä, P., Heikkilä, T., Kilpeläinen, P., Järviluoma, M. and Gambao, E. "Extending automation of building construction - Survey on potential sensor technologies and robotic applications," Automation in Construction, 36: 168-178, 2013. DOI 10.1016/j.autcon.2013.08.002

[39] Bradley, D., Seward, D., Mann, J. and Goodwin, M."Artificial intelligence in the control and operation of construction plant - the autonomous robot excavator," Automation in Construction, vol. 2, no. 3, pp. 217-228, 1993. DOI 10.1016/0926-5805(93)90042-V

[40] Nguyen, Q.H., Ha, Q.P., Rye, D.C. and Durrant-Whyte, H.F. (2000) "Force/position tracking with sliding mode control for electrohydraulic systems of a robotic excavator", Proc. of the IEEE Conference on Decision and Control (CDC 2000), Sydney Australia, pp. 5524-5529. DOI 10.1109/cdc.2001.914787

[41] Matsuike, T., Sawa, Y., Ohashi, A., Sotozono, S., Fukagawa, R. and Muro, T. "Development of Automatic 
System for Diaphragm-Wall Excavator," in Proc. 13th International Symposium on Automation and Robotics in Construction (ISARC), Tokyo, Japan, 1996. DOI 10.22260/ISARC1996/0036

[42] Ha, Q.P., Santos, M., Nguyen, Q.H., Rye, D.C. and Durrant-Whyte, H.F. "Robotic excavation in construction automation," IEEE Robotics and Automation Magazine, Vol. 9, No. 1, pp. 20-28, 2002. DOI $10.1109 / 100.993151$

[43] Stenz, A., Bares, J., Singh, S., and Rowe, P., “A robotic excavator for autonomous truck loading,” Autonomous Robots, 7(2): 175-186, 1999. DOI 10.1023/A:1008914201877

[44] Tochizawa, M., Takeda, S., Kamada, S., Hirosawa, K., Kikuchi, Y. , Wada, T. and Itoh, S. "Automatic Excavator," in Proc. 8th Int. Symposium on Automation and Robotics in Construction (ISARC), Stuttgart, Germany, 1991. DOI 10.22260/ISARC1991/0028

[45] Saeedi, P., Lawrence, P., Lowe, D., Jacobsen, P., Kusalovic, D., Ardron, K. and Sorensen, P. “An autonomous excavator with vision-based track-slippage control," IEEE Transactions on Control Systems Technology, 13(1): 67-84, 2005. DOI 10.1109/TCST.2004.838551

[46] Schmidt, D. and Berns, K. "Construction site navigation for the autonomous excavator Thor", in Proc. 2015 6th International Conference on Automation, Robotics and Applications (ICARA), Queenstown New Zealand, 2015. DOI 10.1109/ICARA.2015.7081130

[47] Abouaf, J. “Trial by fire: teleoperated robot targets Chernobyl," IEEE Computer Graphics and Applications, 18: 10-14, 1998. DOI 10.1109/38.689654

[48] Schiffbauer, W., Yenchek, M., and Lutz, T. "Remote vision system for bulldozers on coal stockpiles," in Proc. 42nd IEEE Annual Meeting and Conference Industry Applications, 2007. DOI 10.1109/07IAS.2007.317

[49] Minamoto, M., Kawashima, K., and Kanno, T. "Effect of force feedback on a bulldozer-type robot," in Proc. IEEE Int. Conf. Mechatronics and Automation (ICMA'16), 2016. DOI 10.1109/ICMA.2016.7558908

[50] Autonomous Solutions Inc., "About Robotic bulldozers from ASI," ASI Robots Inc., [Online], Available: https://www.asirobots.com/mining/dozer/. [Accessed 15 Jan 2018].

[51] Muro, T. "An Optimum Operation of a Bulldozer Running on a Weak Terrain," in Proceedings of the 5th International Symposium on Automation and Robotics in Construction (ISARC'88), Tokyo, Japan, vol. 2, pp. 717-726, 1988. DOI 10.1016/0022-4898(91)90037-7

[52] Moghaddam, R. Y., Kotchon, A. and Lipsett, M. "Method and apparatus for on-line estimation of soil parameters during excavation," Journal of Terramechanics, 49(3-4): 173-181, $2012 . \quad$ DOI 10.1016/j.jterra.2012.05.002

[53] Ito, N. "Bulldozer blade control," Journal of Terramechanics, 28: 65-78, 1991. DOI 10.1016/00224898(91)90007-S

[54] Peurifoy, R. L., Schexnayder, G. J. and Shapira, A. Construction Planning, Equipment and Methods, $7^{\text {th }}$ Ed., McGraw-Hill Higher Education, 2006. ISBN 978-0073401126

[55] Sun, D. I., Kim, S. H., Lee, Y. S., Lee, S. K. and Han, C. S. "Pose and Position Estimation of Dozer Blade in 3-dimensional by Integration of IMU with Two RTK GPSs," in ISARC. Proc. Int Symp. on Automation and Robotics in Construction, 2017. DOI 10.22260/ISARC2017/0137

[56] Mueller, R., Wilkinson, A., Gallo, C., Nick, A., Schuler, J., and King, R. "Lightweight bulldozer attachment for construction and excavation on the lunar surface," in Proceedings of AIAA Space, 2009. DOI $10.2514 / 6.2009-6466$

[57] Israeli MOD. "Israeli Army Introduces Unmanned Bulldozers," Defence Talk, 27 Sep 2011. Online: https://www.defencetalk.com/israeli-army-introduces-unmanned-bulldozers-37260/, [accessed 25 FEB 2018].

[58] Habib, M. (Ed.), Humanitarian Demining: Innovative Solutions and the Challenges of Technology, I-Tech Education and Publishing, Vienna, Austria, 2008. ISBN 978-3-902613-11-0

[59] Santana, P. and Barata, J. "A multirobot system for landmine detection," in Proceedings of the 10th IEEE Conference on Emerging Technologies and Factory Automation, Catania, Italy, 2005. DOI 10.1109/ETFA.2005.1612597

[60] Cobo, M., Ingram, R., and Cetinkunt, S. "Modeling, identification, and real-time control of bucket hydraulic system for a wheel type loader earth moving equipment," Mechatronics, 8: 863-885, 1998. DOI 10.1016/S0957-4158(98)00038-

[61] Aguilera, S., Torres-Torriti, M., and Auat, F. "Modeling of skid-steer mobile manipulators using spatial vector algebra and experimental validation with a compact loader," in Proceedings of the IEEE/RSJ International Conference on Intelligent Robots and Systems (IROS' 14), 2014. DOI 10.1109/IROS.2014.6942776

[62] Ordonez, C., Gupta, N., Reese, B., Seegmiller, N., Kelly, A. and Collins Jr, E. G. "Learning of skid-steered kinematic and dynamic models for motion planning," Robotics and Autonomous Systems, 95: 207-221, 2017. 
DOI 10.1016/j.robot.2017.05.014

[63] Lever, P. "An automated digging control for a wheel loader," Robotica, 19: 497-511, 2001. DOI $10.1017 / \mathrm{S} 0263574701003435$

[64] Volvoce http://www.volvoce.com/-/media/volvoce/global/global-site/our-offer/brochures/volvo-constructionequipment-reveals-prototype-autonomous-machines-final-16-09.pdf? v=bE4yPw [Accessed 14 Jan 2018].

[65] Levy, A. “CNBC,” Built Robotics, 1910 2017. [Online], Available: https://www.cnbc.com/2017/10/18/builtrobotics-raises-15-million-from-nea-for-autonomous-construction.html. [Accessed 14 Jan 2018].

[66] Heikkilä, R. and Jaakkola, M. "Intelligent road construction site - development of automation into total working process of Finnish road construction," in Proceedings of the 20th International Symposium on Automation and Robotics in Construction (ISARC'03), pp. 265-269, Eindhoven, Holland, 2003. DOI 10.22260/ISARC2003/0046

[67] Fukukawa, M. and Yamaguchi, T. "Application of 3-D-MC for Road Construction Machine," in Proceedings of the 21st International Symposium on Automation and Robotics in Construction (ISARC'04), Jeju, Korea, 2004. DOI 10.22260/ISARC2004/0014

[68] Diss, K. "Driverless trucks move all iron ore at Rio Tinto's Pilbara mines, in world first", Online: www.abc.net.au/news/2015-10-18/rio-tinto-opens-worlds-first-automated-mine/6863814 [Accessed Sep 2018]

[69] Biswal, B. and Choudhury, B. "Cooperative Task Planning of Multi-Robot System," in Proceedings of the 24th International Symposium on Automation and Robotics in Construction (ISARC'07), pp. 211-216, India, 2007. DOI 10.1109/ROBOT.2003.1241969

[70] Ren, Z. and Anumba, C. "Multi-agent systems in construction state-of-the-art and prospect - A review," Automation in Construction, vol. 13, pp. 421-434, 2004. DOI 10.1016/j.autcon.2003.12.002

[71] Kwok, N.M., Ha, Q.P. and Fang, G. "Motion Coordination for Construction Vehicles using Swarm Intelligence," Int. Journal of Advanced Robotic Systems, Vol. 4, No. 4, pp. 469-476, 2007. DOI 10.5772/5672

[72] Kim, S.-K. and Russell, J. "Framework for an intelligent earthwork system Part II - Task identification/scheduling and resource allocation methodology," Automation in Construction, 12(1): 15-27, 2003. DOI 10.1016/S0926-5805(02)00033-X

[73] Task Group IST-032/RTG-014, Multi-Robot Systems in Military Domains, RTO Technical Report No. TRIST-032 for NATO, 2008.

[74] Singh, S. and Thayer, S. Autonomous Robots for Military Systems, Technical Report No. CMU-RI-TR-01-16, the Robotics Institute, Carnegie Mellon University, Pennsylvania, 2010.

[75] Lavery, K., "Convoy of Connectivity: U.S. Army Tests Autonomous Trucks in Michigan,” WKAR, 8 Nov 2016. Online: $\quad$ http://wkar.org/post/convoy-connectivity-us-army-tests-autonomous-trucks-michigan\#stream/0, [Accessed 5 MAR 2018]

[76] Caterpillar https://www.cat.com/en_US/articles/customer-stories/forestry/land-clearing-done-remotely.html [Accessed 5 MAY 2018]

[77] US Military Bases, "FOB Delaram Marine Corps Base in Delaram, Afghanistan,” Military Bases. Online: https://militarybases.com/overseas/afghanistan/fob-delaram/, [accessed 15 JAN 2018]

[78] Tekin, Y., Kul, B., and Okursoy, R. "Sensing and 3-D mapping of soil compaction", Sensors, 8(5): 3447-3459, 2008. DOI 10.3390/s8053447

[79] Gamgadhraiah, S. and Umashankar, H. "Network Centric Warfare: A Survey," International Journal of Computer Networks and Wireless Communications, 4(1): 20-25, 2014.

[80] Holloway, J. "British Army takes remote-control of Terrier, the digging-est dog of war," New Atlas, June $6^{\text {th }}$, 2013. Online: https://newatlas.com/bae-systems-terrier/27819/ [Accessed 17 February 2018].

[81] RioTinto http://www.riotinto.com/media/media-releases-237 15732.aspx [accessed 12 February 2018]

[82] Yu, Y.-H., Kwok, N. and Ha, Q. "Color Tracking for Multiple Robot Control using a System-onProgrammable-Chip", Automation in Construction, 20(6): 669-676, 2011. DOI 10.1016/j.autcon.2011.04.013

[83] Hislop, D., Coombs, C., Taneva, S., and Barnard, S. "Rapid evidence review: Impact of artificial intelligence, robotics and automation technologies on work," Chartered Institute of Personnel and Development, 2017 Report. [Online], Available: https://www.cipd.co.uk/knowledge/work/technology/artificial-intelligenceworkplace-impact [Accessed 23 Mar 2018]

[84] Jentsch, F. and Barnes, M. Human-Robot Interactions in Future Military Operations, CRC Press, 2017. DOI 10.1108/ir.2011.04938eaa.010

[85] Budny, E., Szynkarczyk, P. and Wrona, J. "Unmanned Ground Military and Construction Systems Technology Gaps Exploration", Proceedings of the 34th Int. Symp. Automation and Robotics in Construction (ISARC), pp. 577-581, Taipei, Taiwan, 2017. DOI 10.22260/ISARC2017/0080. 